\title{
Rheological Behaviour of Stabilized Diamond-Graphene Nanoplatelets Hybrid Nanosuspensions in Mineral Oil
}

\author{
Suhaib Umer Ilyas ${ }^{\mathrm{a}^{*}}$, Syahrir Ridha ${ }^{\mathrm{a}, \mathrm{b}}$, Suneela Sardar ${ }^{\mathrm{c}}$, Patrice Estellé ${ }^{\mathrm{d}}$, Abhishek Kumar ${ }^{\mathrm{b}}$, \\ Rajashekhar Pendyala ${ }^{\mathrm{e}}$ \\ ${ }^{a}$ Institute of Hydrocarbon Recovery, Universiti Teknologi PETRONAS, 32610 Seri Iskandar, Perak Darul \\ Ridzuan, Malaysia \\ ${ }^{\mathrm{b}}$ Petroleum Engineering Department, Universiti Teknologi PETRONAS, 32610 Seri Iskandar, Perak Darul \\ Ridzuan, Malaysia \\ ${ }^{c}$ School of Chemical and Process Engineering, University of Leeds, Leeds, LS2 9JT, United Kingdom \\ ${ }^{\mathrm{d}}$ Univ Rennes, LGCGM, 35000 Rennes, France \\ ${ }^{\mathrm{e}}$ Chemical Engineering Department, Universiti Teknologi PETRONAS, 32610 Seri Iskandar, Perak Darul \\ Ridzuan, Malaysia \\ *Corresponding Author: suhaib.ilyas@utp.edu.my
}

\begin{abstract}
Recent advancements in thermo-fluid technology assisted with highly thermal conductive nanomaterials have shown assuring outcomes. It is also proven that thermal conductivity alone cannot define the overall heat transfer characteristics, and the viscous properties are equally significant towards thermal management. Therefore, this research involves investigating the rheological behavior of hybrid nanosuspensions containing high thermally conductive diamond and graphene nanoplatelets $(1: 1)$. These nanomaterials are dispersed in mineral oil using a two-step technique. Hybrid nanofluids' stability is achieved using a non-ionic stabilizer Span85, exhibiting no sedimentation for a minimum of five months. Nanomaterial characterizations are performed to study morphology, purity, and chemical analysis. The flow behavior of hybrid nanosuspensions is investigated at varying nanomaterial mass concentrations ( $0-2 \%)$, temperatures $(298.15-338.15 \mathrm{~K})$, and shear rates $\left(1-2000 \mathrm{~s}^{-1}\right)$. Hybrid nanofluids exhibit shear-thinning behavior, which is also correlated with the Ostwald-de-Waele model. The temperature-viscosity relationship is well predicted using the Vogel-Fulcher-Tammann model. Hybrid nanofluids show a maximum enhancement of $35 \%$ viscosity at $2 \%$ concentration. A generalized twovariable correlation is used to express viscosity as a function of temperature and nanofluid concentration with an excellent agreement. Three different machine learning methods, i.e., Artificial Neural Network (ANN), Gradient Boosting Machine (GBM), and Random Forest (RF) algorithms are also introduced to predict the viscosity of hybrid nanofluids based on the three input parameters (temperature, concentration, and shear rate). The parity plots conclude that all algorithms can predict big-data viscous behavior with high precision.
\end{abstract}

Keywords: Diamond; Graphene Nanoplatelets; Hybrid Nanofluid; Machine Learning; Mineral Oil; Rheology.

\section{Introduction}

The continuous increase in global energy demand and consumption has motivated researchers towards thermal management and energy optimization. Nanofluids can play a key role in thermal management due to superior thermal properties. The research on nanofluid technology is tremendously progressed 
in recent years. The introduction of nanomaterials in conventional fluids, termed as nanofluids, modifies positively the physical, optical, electrical, and magnetic properties of the fluid [1,2]. The initial research on nanofluids two decades ago was primarily focused on increasing the thermal conductivity of fluids by adding metallic, non-metallic, carbon-based, and polymeric nanoparticles. Whereas, fewer contributions were observed towards flow characteristics and other temperature-dependent properties of nanosuspensions. The advancements in nanofluid research have proclaimed that the overall heat transfer performance of fluid may not depend solely on the thermal conductive parameter. Still, the effective viscosity, density, heat capacity, thermal expansion coefficient, and surface tension are equally important. The understanding and consideration of momentum transport during nanofluid operation in different applications is vital in achieving proficient thermal management of energy devices. A recent report [3] has stated several challenges in nanofluid technology towards industrial applications, such as low stability, increased pumping power for forced convective applications, reliability of conventional models, correlations, and reported experimental data.

Highly Refined Mineral Oils (HRMO) are generally used in several heat transfer applications where high-flux conditions or electrically insulating conditions are required, such as distributor transformer cooling, reactor cooling jackets, sub-merged cooling of electronic devices, automobile engine management, etc. [4,5]. Oil-based nanofluids are still not a well-developed research area but recently reported studies [6] had explored its potential in several applications. These applications of HRMO are not limited to heat transfer only, but it is also used in Enhanced Oil Recovery (EOR), cosmetics, food, lubrication, solar, and biomedical applications [7-10]. Asadi et al. [5] stated in a review study that nanofluids (oil-based) generally have a higher viscosity than the conventional liquids, which can increase the pumping power. Therefore, it might not be favorable for the heat transfer operation. The viscous properties are influenced by nanomaterial type, size, loadings, shear rate, and temperature. Therefore, it is essential to understand the flow behavior of nanofluids. Reported studies have mentioned the potential of HRMO with nano-additives as an excellent lubricating agent with anti-wear, reduced friction, tribological potential, and with the characteristics of improved load carrying capacity $[11,12]$.

Several experimental studies have been published on the thermal and viscous transport properties of hybrid nanofluids in recent years. From a practical point of view, it is also possible that the flow behavior of nanofluids may exhibit Newtonian or non-Newtonian flow characteristics depending on the nanoparticle type, dimensions, and concentrations [13]. Zyła et al. [14] experimentally measured the rheological behavior of nano-diamond dispersions in ethylene glycol-based nanofluids. The nanofluids showed non-Newtonian behavior, referring to Herschel-Bulkley fluids. It was also observed that the viscosity of nanofluids increased with the diamond fraction. In an investigation on rheological studies of carbon black/ethylene glycol nanofluids by Zyla [15], it was found that the lowest concentration $(0.001 \%)$ showed the Newtonian character. However, all other nanofluid concentrations exhibited nonNewtonian shear thinning behavior. Heris et al. [16] experimentally investigated rheological characteristics of $\mathrm{ZnO}$-based nano-lubricants with varying concentrations from $0.1 \%$ to $4 \%$. It was observed that nanofluids exhibited non-Newtonian Bingham fluid behavior.

Several reported studies $[17,18]$ have suggested that hybrid nanofluids in the fluids could exhibit enhanced characteristics. Hybrid nanofluids are termed when more than one nanomaterials are added into the conventional liquid $[9,19]$. It is notable to mention that almost all studies referring to hybrid nanofluids have mechanically mixed nanomaterial combinations in different proportions to the base liquid, and there are no chemical interactions/bonding involved among the nanomaterials prior to mixing. Babu et al. [20] stated that hybrid nanofluids have a synergistic effect that could improve rheological characteristics and efficient thermal network. Asadi et al. [21] investigated experimental 
dynamic viscosity of hybrid aqueous nanofluid containing $\mathrm{CuO}$ and $\mathrm{TiO}_{2}$ nanoparticles. All nanofluids exhibited Newtonian character, and the highest concentration (1 vol\%) showed the highest viscosity, $1.74 \mathrm{mPa} \cdot \mathrm{s}$. Yan et al. [22] measured the dynamic viscosity of a hybrid nanofluid containing $\mathrm{MgO}$ and MWCNT dispersions in ethylene glycol. All nanofluids exhibited Newtonian character, and a maximum increase of $168 \%$ was reported for $1 \mathrm{vol} \%$ concentration. Afrand et al. [23] used $\mathrm{SiO}_{2}$ and $\mathrm{MWCNT}^{2}$ hybrid dispersion in SAE40 oil to investigated viscous flow behavior at varying temperatures (298.15$323.15 \mathrm{~K})$ and concentrations ( $0-1$ vol. $\%)$. The viscosity increased by a maximum of $37.4 \%$ and showed Newtonian behavior. Giwa et al. [24] studied the viscosity of water-based hybrid nanofluids containing $\gamma-\mathrm{Al}_{2} \mathrm{O}_{3}$ and MWCNT. They reported a maximum enhancement of $26.3 \%$ in viscosity at $328 \mathrm{~K}$ using a 90:10 ratio of the nanomaterials mentioned above. Tian et al. [25] investigated rheological parameters for CuO-MWCNT dispersions in water/EG (70:30) and reported that the highest nanomaterial concentration exhibited non-Newtonian characteristics. Alarifi et al. [26] experimentally investigated the rheological behavior of $\mathrm{TiO}_{2}-\mathrm{MWCNT}$ hybrid dispersions in oil. The nanofluids were found stable for 14 days, and the maximum enhancement (42\%) was observed at $2 \%$ concentration and $50^{\circ} \mathrm{C}$.

The progression in modeling the nanofluids' viscosity has suggested that the conventional models may not accurately predict nanofluids' thermophysical properties [3,5,27]. These conventional models do not consider agglomeration effect, sorption, double electrical layers, temperature, Brownian motion, etc. in their equations. Thus, underpredicting the effective viscosity of nanofluids, which is observed in many studies [23,28,29]. Banisharif et al. [30] reported that a good agreement with the existing models could be achieved in the nanofluids' thermal conductivity by considering the nanolayer effect, effective medium theory, and Brownian motion. Asadi et al. [5] reviewed and compiled a list of correlations based on experimental data to predict oil-based nanofluids' effective viscosity. These correlations have no physical justifications and are valid for a specific type and range of nanofluids, depending on the trend of experimental data. The reported literature has proposed alternative prediction approaches using machine learning algorithms. Some of the commonly used machine learning techniques in nanofluid thermophysical properties predictions are Artificial Neural Network (ANN), Genetic algorithm (GA), Particle swarm optimization (PSO), radial basis function (RBF), and Least-square support vector machine (LSSVM), Random Forest (RF), Gradient Boost Method (GBM), etc. [31-33]. Dalkilic et al. [34] compared ANN predictions with the existing correlations for graphite/water nanofluid's dynamic viscosity. It was reported that the ANN method was better than correlation development. Gholizadeh et al. [35] used RF approach to predict the viscosity of metallic oxides-based nanofluids and reported $0.989 \mathrm{R}^{2}$ for the model accuracy using multi-input parameters. It is noteworthy to mention that while the results obtained by machine learning predictive methods proliferate, the inner working of these tools remains elusive when it comes to physical insights or scientific principles. The flow of network processes information to solve a problem is often unclear. These predictive methods only depend on the number of data points, algorithm and trend of data provided.

Carbon-based nanomaterials generally possess high thermal conductivity [36], and several research groups are focusing on diamond and graphene nanomaterials to fully understand their potential in different applications. Diamond nanoparticles possess interesting mechanical, optical, thermal, and electrochemical properties. The high thermal conductivity of diamond nanoparticles makes it an ideal candidate for nanofluids-based thermal systems. It has a thermal conductivity of $2200-3320 \mathrm{~W} / \mathrm{m} \cdot \mathrm{K}$ due to low photon scattering and strong carbon covalent bonding [37]. Besides high thermal conductivity, it has negligible electrical conductivity $(\sim 0.01 \mathrm{nS} / \mathrm{m})$, which may have great potential for electronic cooling systems. Graphene nanomaterials are competitive with unique thermal, mechanical, optical, and electrical properties [38]. It has a 2D structure with strong covalent bindings in the form of 
a hexagonal carbon network. It has proven to be a significant agent for high-frequency nanoelectronics, supercapacitors, chemical sensors, EOR, etc. [39-41].

This research aims to investigate the rheological behavior of hybrid nanofluid with different concentrations of diamond nanoparticles and graphene nanoplatelets dispersions in HRMO. Both nanomaterials are among the highest thermal conductive materials. It is believed that this combination in HRMOs-based nanofluids may provide and explore a new class of advanced nanofluid for thermal management issues. Therefore, these nanofluids' flow behaviour is experimentally studied in this research at varying mass concentrations, shear rates, and temperature. It is also notable that such a combination of hybrid nanofluid has not been subjected to research before. Thus, exhibiting the novelty of this research. Initial nanomaterial characterizations are performed to study morphology, topology, crystalline nature, and chemical purity composition. The hybrid nanofluids are then prepared using a non-ionic surfactant, and stability is evaluated for over five months. A rotational rheometer is used to analyze the viscosity of hybrid nanofluids experimentally. Different models and correlations are applied to express and characterize the nature of rheology experiments. Three machine learning approaches have also been utilized to predict complete experimental data of viscosity of hybrid nanofluids.

\section{Methodology}

\subsection{Materials}

A combination of two nanomaterials is used in this research, i.e., diamond nanoparticles and graphene nanoplatelets. Diamond nanoparticles are acquired from US Research Nanomaterials, Inc. (USA), having nearly spherical morphology with an average diameter size of 3-10 nm and specific surface area (SSA) of $272 \mathrm{~m}^{2} / \mathrm{g}$. The true density of diamond nanoparticles is $3.05-3.30 \mathrm{~g} / \mathrm{cm}^{3}$ with a purity of $>98.3 \%$. Graphene nanoplatelets are acquired from Sigma-Aldrich Malaysia with $750 \mathrm{~m}^{2} / \mathrm{g} \mathrm{SSA}$. The average size of the nanoplatelet is $<2 \mu \mathrm{m}$, and an average thickness of $10 \mathrm{~nm}$. The molecular weight of nanoplatelets is 12.01 , and the true density is $2.25 \mathrm{~g} / \mathrm{cm}^{3}$. A hybrid nanomaterial system is created by adding diamond nanoparticles and graphene nanoplatelets in an equal mass ratio (1:1) in the base fluid. Both nanomaterials are not chemically bonded and dispersed in the oil without any alteration; thus, the structure and dimensions of nanomaterials are not affected.

The base fluid is highly refined mineral oil (HRMO), Caltex Texatherm 32, consisting of 70-99 wt\% hydrocarbons (C15-C50). Non-ionic sorbitane trioleate (Span 85) is used as a stabilizing agent acquired from Sigma-Aldrich, Malaysia. These specifications of nanomaterials and the base-fluid are provided by manufacturing companies, and investigations are performed without altering any chemical or mechanical nature of the materials. However, characterizations are performed in this research to verify the morphology and purity of nanoparticles.

\subsection{Nanoparticle Characterization}

Different characterization techniques are used to confirm the structure, morphology, and elemental composition of nanomaterials and diamond and graphene nanoplatelets hybrid mixtures. In this research, Field Emissions Scanning Electron Microscopy (FESEM), (Zeiss-Supra 55VP, Germany), is employed to study the morphological feature of diamond and graphene nanoplatelets. Samples for FESEM analysis are prepared by dispersing the nanomaterials in the acetone and ultrasonically vibrated for several minutes. A droplet from the obtained suspension is transferred to the clean aluminium stub and dried for a few minutes. Nanomaterials are inspected for morphological characterization using Transmission Electron Microscopy (TEM), (Hitachi HT7830UHR, Japan), for crystallinity. 
Nanoparticles were dispersed in acetone by sonication and drops of formed suspensions were introduced onto holey carbon-coated copper grids for analysis. Energy Dispersive X-ray (EDX) spectroscopy is used for the estimation of elemental composition. Structural characterization of nanomaterials is performed using powder X-ray Diffraction (XRD), (Bruker D8, USA), employing $\mathrm{CuK} \alpha$ radiation $\left(\lambda=1.5418 \mathrm{~A}^{\circ}\right)$ at ambient conditions. For XRD, scans are performed over a $2 \theta$ ranges from $20-70^{\circ}$ with a step size of $0.1^{\circ}$. In addition to structural and morphological features, Fourier Transform Infrared Reflection spectroscopy (FTIR) is used to determine the qualitative features of IRactive molecules in nanomaterials. It can also provide information about the light elements such as $\mathrm{H}$ and $\mathrm{C}$ in inorganic substances. In this research, the experiment is carried out by FTIR (Perkin Elmer, USA) with a diamond iTR attenuated total reflectance (ATR) sampling accessory. The spectra are taken over the wavenumber ranging $400-4000 \mathrm{~cm}^{-1}$ and 36 scans are used per spectrum.

\subsection{Preparation and Stability of Nanofluids}

The hybrid nanofluids are prepared by mechanically mixing diamond nanoparticles and graphene nanoplatelets in equal mass proportions (1:1) and dispersing into HRMO using the two-step method. Generally, the solid nanomaterials are prone to settle down due to aggregation among particles $[42,43]$. This aggregation is subjected to surface interaction of nanomaterials, where Van der Waal attractive forces are the strongest. Hence, increasing the primary size of the nanomaterials to a micron-level and settling down due to gravity. A destabilized nanofluid is considered not valid for any practical application. Therefore, it is essential to evaluate the stability of nanofluids prior to any thermophysical property measurement. In this research, the ultrasonication method and a non-ionic surfactant are utilized to stabilize hybrid nanomaterials in HRMO for a longer time. An ultrasonic homogenizer (probe), (Biologics 150V/T, USA), is used with frequency $20 \mathrm{kHz}$. The optimized ultrasonic parameters are taken from previous studies $[41,44,45]$, i.e., $1 \mathrm{hr}$ operation, $30 \%$ pulse and $70 \%$ power. This indicates that each nanofluid sample is ultrasonicated with a $70 \%$ power of the equipment's total ultrasonic frequency. The pulse indicates the cycle time (on/off), which is set at $30 \%$ for safer operation of the equipment. A water bath is used to avoid heating the hybrid nanofluid sample during ultrasonic operation. A non-ionic surfactant, Span 85, is used to stabilize hybrid nanoparticles in HRMO. The basis of choosing non-ionic surfactant in this research is that it does not aid in corrosion during operation. It has high thermal stability, non-toxicity, environment-friendly, non-foaming quality during operation, and highly compatible with HRMO. Generally, non-ionic stabilizers have no charge at the hydrophilic end, and the linkage of particles and base fluid relies on steric hindrance only [46]. Therefore, a higher quantity of non-ionic surfactant may be required compared to ionic surfactants to achieve better nano-dispersion. In this research, hybrid nanofluids are prepared at six different mass concentrations i.e., $0,0.4 \%, 0.8 \%, 1.2 \%, 1.6 \%$ and $2 \%$. Few experiments are conducted to find the optimum concentration of surfactant required to stabilize nanofluid. The optimum mass concentration of hybrid nanomaterial to surfactant (Span85) ratio is found to be 1:5. The evaluation of stability is performed by visual inspection. Several studies have performed zeta potential analysis and UV-Vis UVVis Spectroscopy to evaluate stability. However, these analyses are not included in this research. Zeta potential is highly dependent on the $\mathrm{pH}$ of the nanofluid system. This research involves mineral oil as a base fluid which does not have $\mathrm{pH}$; hence, zeta potential analysis might not give results precisely. Furthermore, the concentrations of hybrid nanofluids are relatively high than dilute fluid. The UV-Vis light beam is unable to pass through the dense sample concentration; hence, unable to detect any measurement. Therefore, only visual analysis is performed to investigate the stability of nanofluids. The experiments to characterize rheology is performed for the fresh samples of hybrid nanofluids containing stabilizer. The addition of surfactant may change the overall viscosity of nanofluid [47,48]. Therefore, 
a comparative experimental investigation is also performed (Section 3.3.3) to evaluate the impact of surfactant on the effective viscosity.

\subsection{Rheology Experiments and Validation}

The rheological behavior of diamond-graphene nanoplatelets-based hybrid nanofluids is experimentally measured by the DHR1 rheometer by TA Instruments (USA) under steady shear flow conditions. The temperature is kept constant for each shear ramp conditions set at 10 data points per decade from shear rate 1 to $2000 \mathrm{~s}^{-1}$. The shear ramp conditions are used at five different temperatures for all samples, i.e. $298.15 \mathrm{~K}, 308.15 \mathrm{~K}, 318.15 \mathrm{~K}, 328.15 \mathrm{~K}$, and $338.15 \mathrm{~K}$. The geometry of the rheometer is steel-made cone and plate with a $2^{\circ}$ cone angle, $55 \mu \mathrm{m}$ truncation gap, and $60 \mathrm{~mm}$ diameter. The temperature of the system is controlled by a Peltier-plate system with $0.05 \mathrm{~K}$ accuracy. The readings are measured at a constant shear rate/time step. Initially, a constant volume of sample is carefully introduced in the testing cell rested for a few minutes before the operation to avoid bubble formation. Fresh samples are utilized for repeatability and each shear ramp at different temperatures. The test cell is carefully cleaned by solvents after each shear ramp test.

The uncertainty in the measurements is evaluated by following the methodology adopted in the literature [49-51]. Figure 1(a) presents the repeatability data for HRMO at temperature-ramp conditions from $298.15 \mathrm{~K}$ to $338.15 \mathrm{~K}$. The viscosity is measured for five fresh samples of HRMO at a constant shear rate of $500 \mathrm{~s}^{-1}$. The repeatability of the sample shows an average standard deviation (SD) of $0.064 \%$ and average relative SD of $2.55 \%$. The $0.8 \%$ nanofluid sample is tested at three different temperatures (i.e., $298.15 \mathrm{~K}, 318.15 \mathrm{~K}$, and $338.15 \mathrm{~K}$ ) and a constant shear rate of $500 \mathrm{~s}^{-1}$ to check the thermal stability and accuracy of the measurements, shown in Figure 1(b). The readings are taken every 31 seconds for a total of 1400 seconds. It is observed that the nanofluid is capable of withstanding high temperature, and the slight deviations in viscosity readings are almost negligible. Figure 1(b) also proves that effective viscosity values are repeatable over a wide range of time and temperature. The extended uncertainty in measurements is calculated by evaluating the maximum possible error, shown in Figure 1(c). The calculation procedure is detailed in previous work [44]. The declared expanded uncertainty was evaluated to be $5.51 \%$ using $95 \%$ confidence (coverage factor $\mathrm{k}=2$ ). Relative deviations (\%) between the experimental viscosity of HRMO and reported studies [52-57] at varying temperatures are shown in Figure 1(c). The average absolute deviation (AAD) is $4.84 \%$ between the experimental viscosity and previously reported studies [52-57]. 

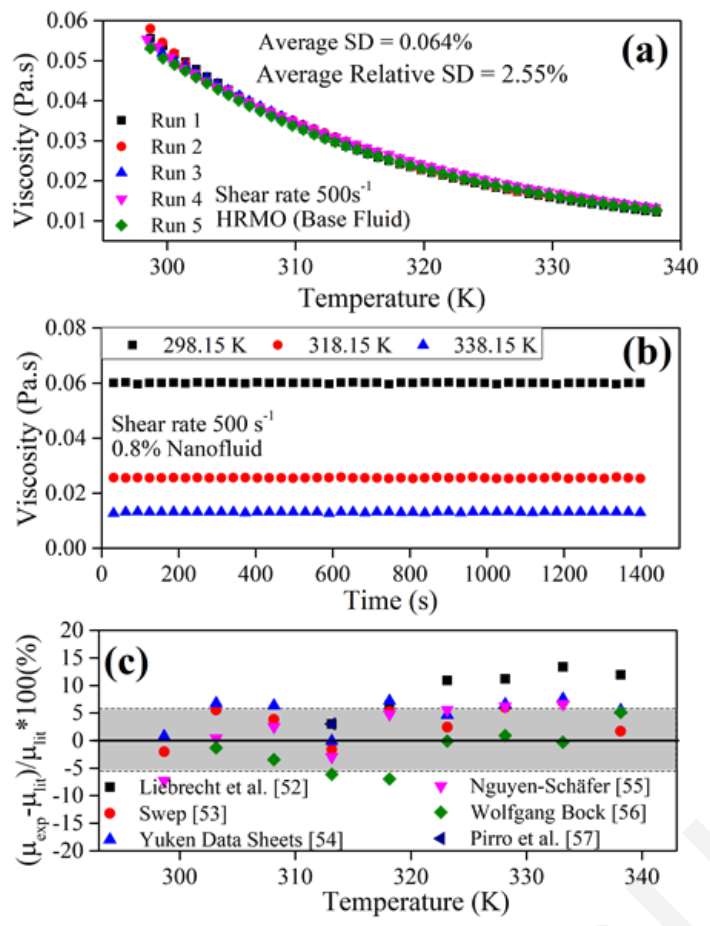

Figure 1: (a) Repeatability of experimental measurements; (b) Dynamic viscosity of $0.8 \%$ nanofluid measured by the rheometer every 31 seconds; (c) Comparative analysis of experiments and the literature [52-57], and declared expanded uncertainty [44] (shaded area).

\subsection{Rheology Parameters and Multivariable Correlation}

This research involves the application of the Ostwald-de-Waele model [58,59] to examine the flow characteristics of hybrid nanofluids, see later equation (9). The flow behavior and consistency index are evaluated at varying temperatures and hybrid nanomaterial concentrations. The most popular expression to correlate the viscosity-temperature relationship of liquids is the Vogel-Fulcher-Tammann (VFT) equation [60], which is a well-known modification of Andrade's equation [61]. In this research, the VFT model is applied to the experimental investigations, and the fitting parameters are tabulated for nanofluids sample. A similar methodology was also applied in a recent study by Cherecheş et al. [61] to correlate the temperature dependence of dynamic viscosity for alumina-based nanofluids enhanced with ionic liquids. Experimental measurements of thermophysical properties are vital for the practical design of thermal systems. Since recent developments in nanofluid technology have suggested that the conventional models may not be suitable for accurate predictions of temperature-dependent properties. This deviation can be attributed to the inadvertence of temperature, nanomaterial geometry, Brownian motion, thermophoresis, and agglomeration factors in the classical model [3,5,27]. A recently published comprehensive review [5] on oil-based nanofluids has compiled several multivariable correlations to predict nanofluids' viscosity (oil-based) as a function of temperature, nanomaterial concentration, shear parameters, etc. However, this research involves the two-parameter (temperature and concentration) correlation proposed by Vallejo et al. [50,51], which is an extension of the Vogel-Fulcher-Tammann model [60]. Vallejo et al. [50,51] used volumetric concentrations in their research. Therefore, a conversion equation is used to convert mass concentration (the present work) to volumetric concertation in order to utilize Vallejo et al. [50,51] correlation. Eq. (1) represents the conversion equation from mass concentration $\left(\varphi_{m}\right)$ to volumetric concentration to $\left(\varphi_{v}\right)$ for a hybrid nanofluid system with an equal proportion (1:1) of nanomaterials. $\rho_{b f}$ and $\rho_{n p}$ are the densities of base fluid and nanomaterials. In this research, the experimental density of HRMOs at different temperatures is utilized from previous 
study [27], while the true densities of nanomaterials are used at ambient conditions. The density data provided by the supplier for diamond nanoparticles and graphene nanoplatelets are $3300 \mathrm{~kg} / \mathrm{m}^{3}$ and $2250 \mathrm{~kg} / \mathrm{m}^{3}$, respectively. For instance, the mass concentrations of hybrid nonfluids $(0.4,0.8,1.2,1.6$, 2 mass\%) corresponds to $0.191,0.382,0.574,0.767,0.961$ vol. $\%$, respectively, at $298.15 \mathrm{~K}$.

(1)

5

$$
\varphi_{v}=\left[\frac{0.5 \varphi_{m} \times \frac{\rho_{b f}}{\rho_{n p}}}{\left(1-0.5 \varphi_{m}\right) \times\left(1-\frac{\rho_{b f}}{\rho_{n p}}\right)}\right]_{D}+\left[\frac{0.5 \varphi_{m} \times \frac{\rho_{b f}}{\rho_{n p}}}{\left(1-0.5 \varphi_{m}\right) \times\left(1-\frac{\rho_{b f}}{\rho_{n p}}\right)}\right]_{G N P}
$$

\subsection{Predictions via Machine Learning Algorithms}

The application of machine learning algorithms for predictive analysis of nanofluid properties is extensively found in recent years. The empirical correlations developed based on experimental data and statistical inference may not yield accurate results for a wide range of nanofluids [62,63], especially when multivariable inputs are involved. The ease of representing a physio-chemical process with datadriven machine learning algorithms has increased in the past few years. Different algorithms were implemented in the literature to estimate the viscosity of nanofluids, such as ANN, LSSVM, RF, and ANFIS (Adaptive Neuro-Fuzzy Inference) [35,64].

In this research, the viscosity of the hybrid nanofluids is predicted with three different machine learning algorithms, i.e., ANN, RF, and GBM (Gradient Boosting Machine), using a software tool PYTHON. Predictions from these learning architectures are analyzed, and the performance is determined by several error estimation metrics. ANN is considered as a black box model because it depends on the backpropagation of randomly initialized weights to approximate solution for the targeted output. Random Forest is an ensemble machine learning technique capable of performing regression using multiple decision trees with a statistical technique called bagging. GBM is also an ensemble category algorithm developed by Friedman [65], which uses multiple tree structures upon the loss function gradient to boost its performance and optimize prediction capability [66].

The input parameters for the algorithms are temperature, hybrid nanomaterial concentration, and shear rate. The output parameter is the viscosity of diamond-graphene nanoplatelets hybrid nanofluids. The workflow detailing different processes to predict the viscosity and analyzing the predicted results is shown in Figure 2. The experimental dataset is divided into two separate segments for training the algorithm and testing its robustness. The total size of the experimental data is 1050, and the ratio between the train and test dataset is set at 0.3 . A standard uniform distribution is used to split the original dataset and maintain statistical inference between the test and train data. The data set after split is transformed onto a scale of 0.0 to 1.0 using Eq. (2) and Eq. (3). This approach is utilized for ANN only because RF and GBM employ tree-based structure for prediction. Therefore, RF and GBM architecture are not affected by the scale of input data. Algorithms are trained using the input training data and then evaluated on testing data. The predictions are obtained after convergence on the train and test datasets, based on the statistical error metrics such as coefficient of determination $\left(\mathrm{R}^{2}\right)$, Root Mean Square Error (RMSE), Mean Absolute Error (MAE), Legate and McCabe Index (LM Index, $\mathrm{E}_{\mathrm{L}, \mathrm{M}}$ ), and Willmot index of agreement (W Index, $\mathrm{I}_{\mathrm{A}}$ ), given in Eqs. (4-8), respectively. 


$$
x_{s t d}=\frac{\left(x-x_{\min }\right)}{x_{\max }-x_{\min }}
$$

$$
x_{\text {scale }}=x_{\text {std }} \times\left(x_{\text {max }}-x_{\text {min }}\right)+x_{\text {min }}
$$

$$
R M S E=\sqrt{\frac{\sum_{i=1}^{n}\left(y_{i}-\hat{y}_{i}\right)^{2}}{N}}
$$

$$
M A E=\frac{1}{N} \sum_{1}^{n}\left|y_{i}-\hat{y}_{i}\right|
$$

$$
R^{2}=1-\frac{\sum_{1}^{n}\left(y_{i}-\hat{y}_{i}\right)^{2}}{\sum_{1}^{n}\left(y_{i}-\bar{y}_{i}\right)^{2}}
$$

$$
E_{L, M}=1-\frac{\sum_{i=1}^{i=N}\left|y_{i}-\hat{y}_{i}\right|}{\sum_{i=1}^{i=N}\left|y_{i}-\bar{y}_{i}\right|}
$$

$$
I_{A}=1-\frac{\sum_{i=1}^{i=N}\left(y_{i}-\hat{y}_{i}\right)^{2}}{\sum_{i=0}^{i=N}\left(\left|\left(y_{i}-\bar{y}_{i}\right)\right|+\left(\hat{y}_{i}-\bar{y}_{i}\right)\right)^{2}}
$$

where, $\hat{y}_{i}$ represents the predicted values, and the number of observations is represented by N. $y_{i}$ is the given data point, and $\overline{\mathrm{Y}}_{i}$ is the mean of the given values.

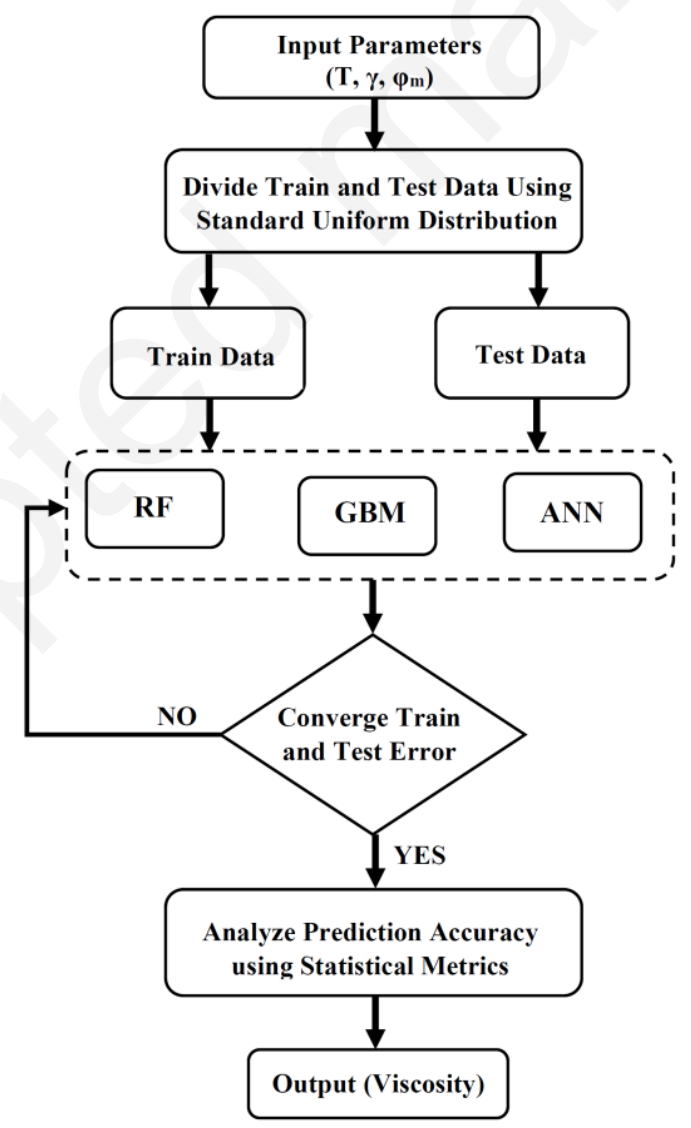

$330 \quad$ Figure 2: The overall flowchart methodology used for viscosity predictions via machine learning algorithms.

\section{Results and discussion}




\subsection{Nanoparticle Characterizations}

\section{4}

335

336

337

\subsubsection{Electron Microscopy}

FESEM is used to understand the size and morphology of the nanomaterials. Micrographs of diamond nanoparticles and graphene nanoplatelets are shown in Figure 3(a, c) and (b, d), respectively. The agglomerates of diamond nanoparticles are observed. Thin layers of graphene nanoplatelets can be clearly seen in the FESEM micrograph along with some fractured surfaces.

TEM image of diamond nanoparticles shows spherical shaped particles with a narrow and consistent size distribution, as seen in Figure 4(a, c). Some big sizes can also be seen solely due to the micro granules of diamond nanoparticles. TEM analysis in Figure $4(\mathrm{~b}, \mathrm{~d})$ reveals the multiple layers of graphene nanoplatelets. Thin layered nanoplatelets of graphene can be seen in the area enclosed with arrows. TEM analysis confirms the primary particle size of diamond nanoparticles in the nanometre range and of graphene nanoplatelets in the micron range, which is in good agreement with the data provided by the supplier. The average size of diamond nanoparticles with spherical morphology is in the range of 3-10 nm, while the average thickness of graphene nanoplatelets is confirmed at $10 \mathrm{~nm}$.
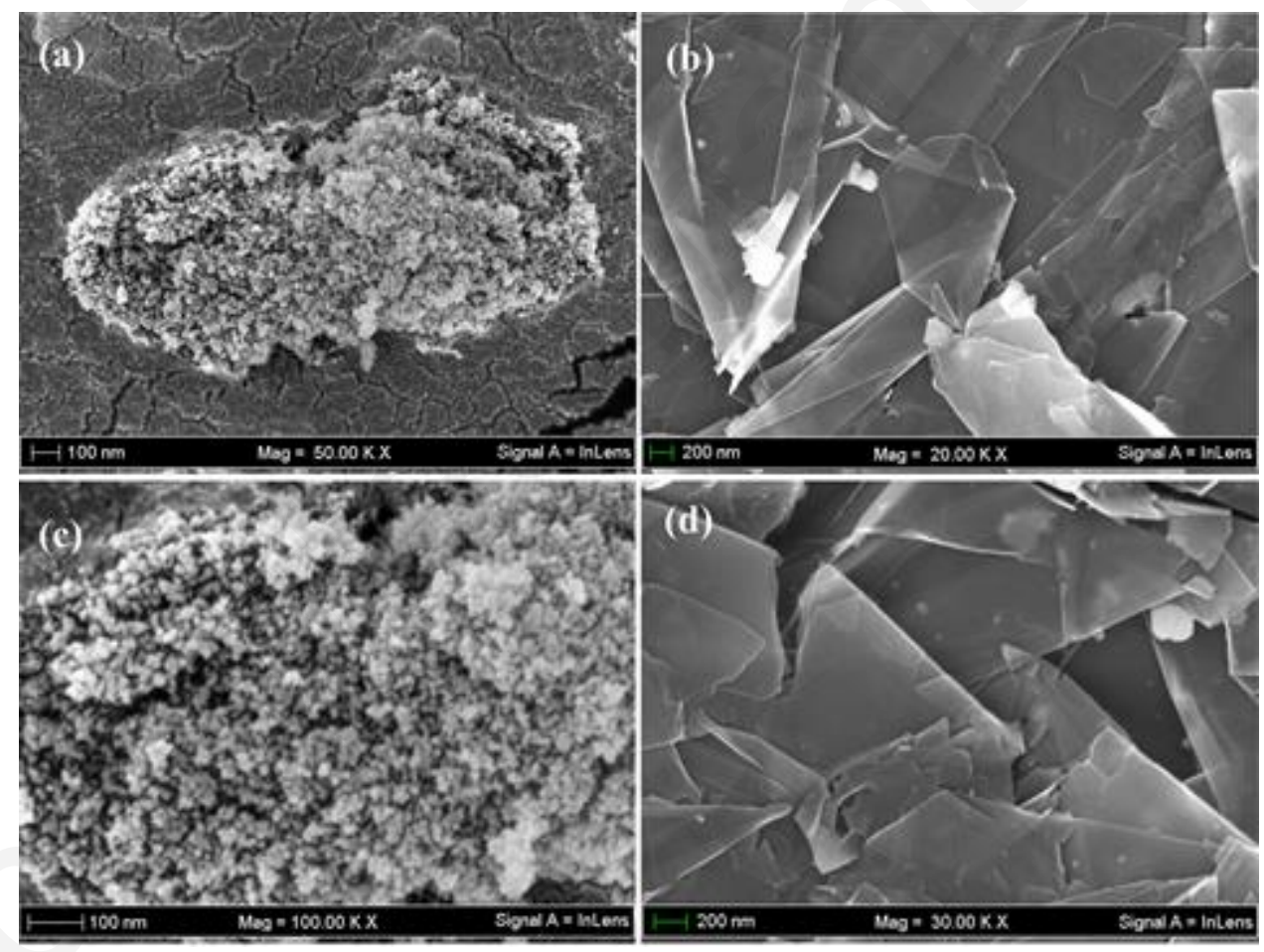

Figure 3: SEM micrographs of (a, c) Diamond nanoparticles and (b, d) Graphene nanoplatelets at different magnifications. 

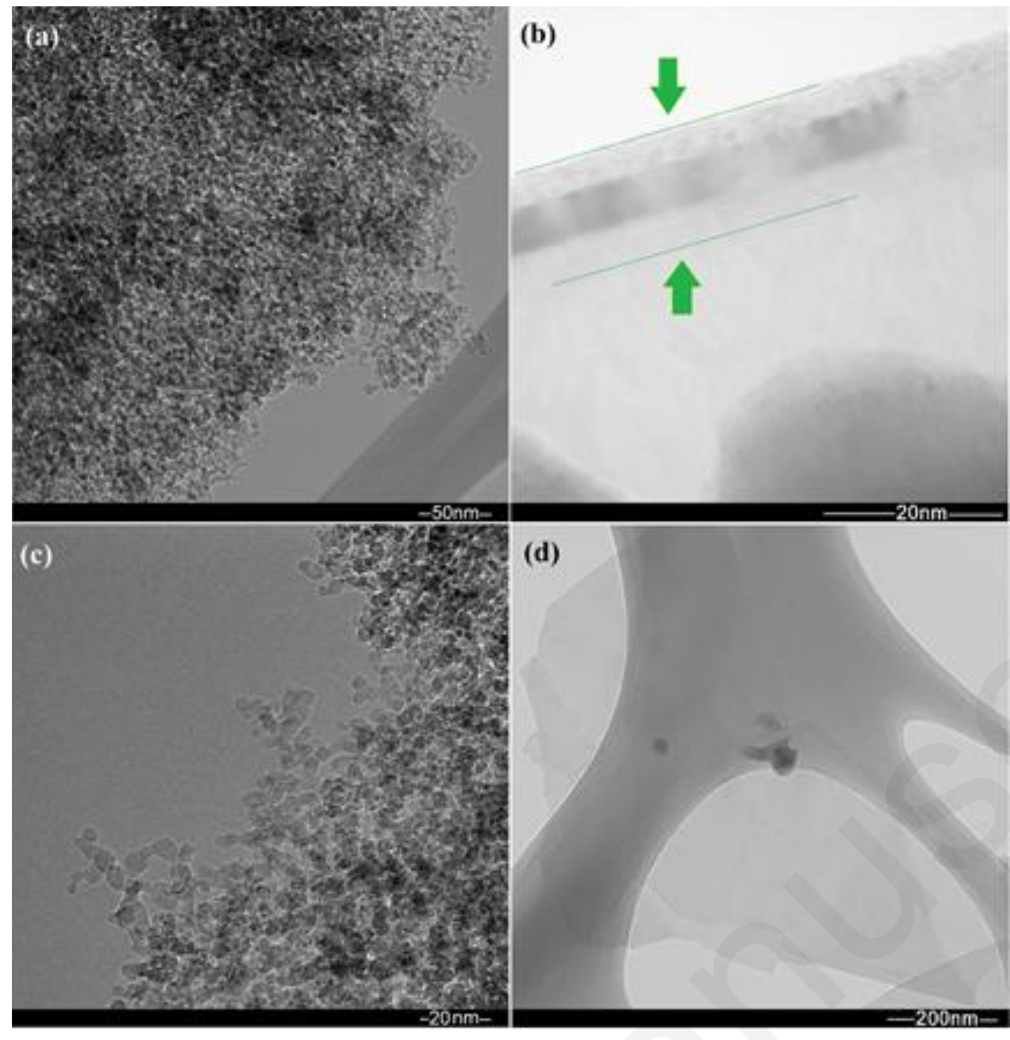

352 Figure 4: TEM images of (a, c) Diamond nanoparticle and (b, d) Graphene nanoplatelets at different magnifications.

\section{$354 \quad$ 3.1.2 Elemental Analysis}

355 EDX spectroscopy is used to study the elemental composition of diamond nanoparticles and graphene 356 nanoplatelets. Figure 5 shows the EDX analysis, and it confirms the presence of mainly Carbon (C) and 357 Oxygen $(\mathrm{O})$ in diamond nanoparticles and graphene nanoplatelets. The weight percentages of elements 358 obtained for diamond nanoparticles are 86.88 for C, 12.97 for O, along with a negligible quantity of 359 Chlorine $(\mathrm{Cl})$. The weight percent of elements obtained from the EDX analysis of graphene 360 nanoplatelets values $96.83 \%$ for $\mathrm{C}$ and $2.03 \%$ for $\mathrm{O}$ with minor impurities of Sulphur (S) and Nitrogen $361(\mathrm{~N})$. EDX analysis of diamond nanoparticles and graphene nanoplatelets confirms the obtained 362 nanomaterials are in a highly pure state. 

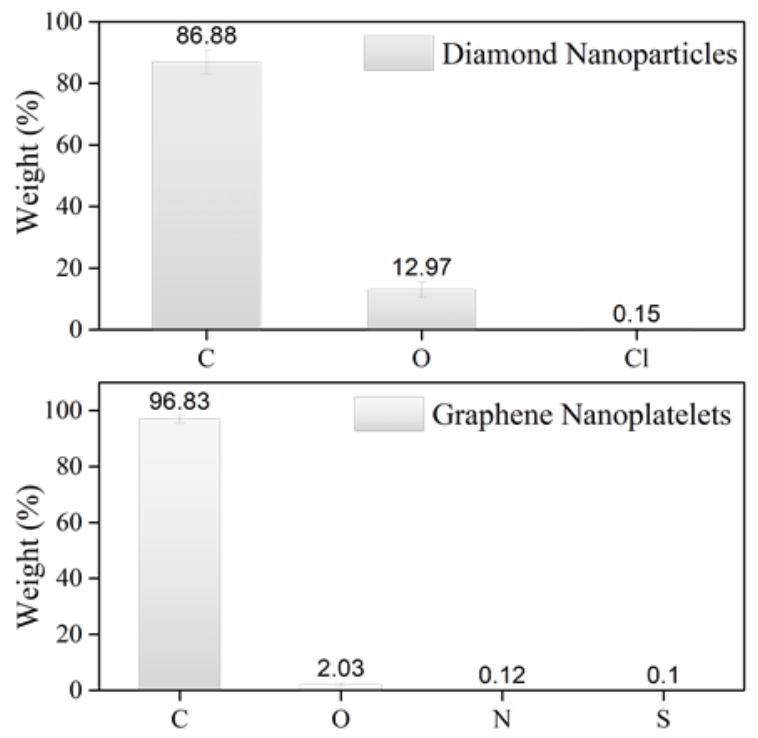

Figure 5: EDX analysis of diamond nanoparticles and graphene nanoplatelets

\subsubsection{XRD Analysis}

XRD analysis is performed on the starting nanomaterials and the obtained hybrid material. Scans of diamond nanoparticles, graphene nanoplatelets, and diamond-graphene nanoplatelets mixture are shown in Figure 6. The observed pattern of diamond nanoparticles shows a significant peak at $2 \theta=44^{\circ}$ with miller indices (111), which is the characteristic peak of diamond nanoparticles [67]. The broadening of the peak is mainly due to the nano-sized crystallites. There appeared no other intense peak between $20^{\circ}<2 \theta<70^{\circ}$, which confirms the purity of this starting material. The XRD scan of graphene nanoplatelets exhibits three reflections. However, the intensities of two minor peaks are compressed in Figure 6, due to the high intensity of one major peak corresponding to the graphene nanoplatelets [33]. The peak appeared at around $2 \theta=26^{\circ}$ is most visible due to its intensity and two minor reflections around positions $45^{\circ}$ and $55^{\circ}$ suppressed due to the scale of other scans. Figure 6 also shows the XRD scan of diamond-graphene nanoplatelets, which is the hybrid material obtained through mechanical mixing of equal quantities of diamond nanoparticles and graphene nanoplatelets. The appearance of peaks in the scan of diamond-graphene nanoplatelets at similar positions, as in the scans of pure materials, confirms the successful formation of the hybrid material.

\subsubsection{FTIR Analysis}

FTIR spectra of diamond nanoparticles and graphene nanoplatelets are shown in Figure 7. The scans are performed over the wavenumber ranging from 400 to $4000 \mathrm{~cm}^{-1}$. The scan of diamond nanoparticles shows the major peak around $3420 \mathrm{~cm}^{-1}$, which can be attributed to the stretching of $-\mathrm{OH}$ mode. A shouldered peak appeared around $1700 \mathrm{~cm}^{-1}$, which is due to the $-\mathrm{OH}$ bending vibration or presence of the carboxyl $(-\mathrm{COOH})$ group on the surface of diamond nanoparticles. Peaks around $1250 \mathrm{~cm}^{-1}$ and $1370 \mathrm{~cm}^{-1}$ correspond to the $\mathrm{CO}$ bending vibration and $-\mathrm{CH}$ bending vibration. The appearance of these two peaks can be attributed to the presence of the ester group $\left(\mathrm{CH}_{3}-\mathrm{COOR}\right)$. Scan of graphene nanoplatelets showed a strong adsorption peak at $3450 \mathrm{~cm}^{-1}$, which can be assigned to the $\mathrm{O}-\mathrm{H}$ stretching. The band appeared around $1700 \mathrm{~cm}^{-1}$ is the characteristic absorption band of $\mathrm{C}=\mathrm{O}$ stretching of ketone and lactone. A band around $1600 \mathrm{~cm}^{-1}$ can be attributed to the carboxyl group. The stretching vibration of $\mathrm{C}-\mathrm{OH}$ group appeared in the form of a peak around $1250 \mathrm{~cm}^{-1}$. 


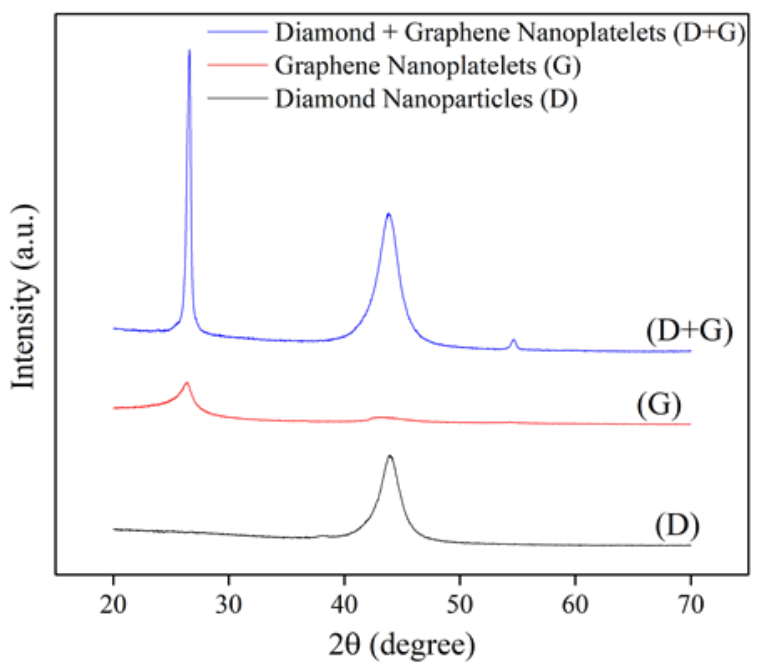

Figure 6: XRD scans of (a) Diamond nanoparticles, (b) Graphene nanoplatelets, and (c) DiamondGraphene nanoplatelets.

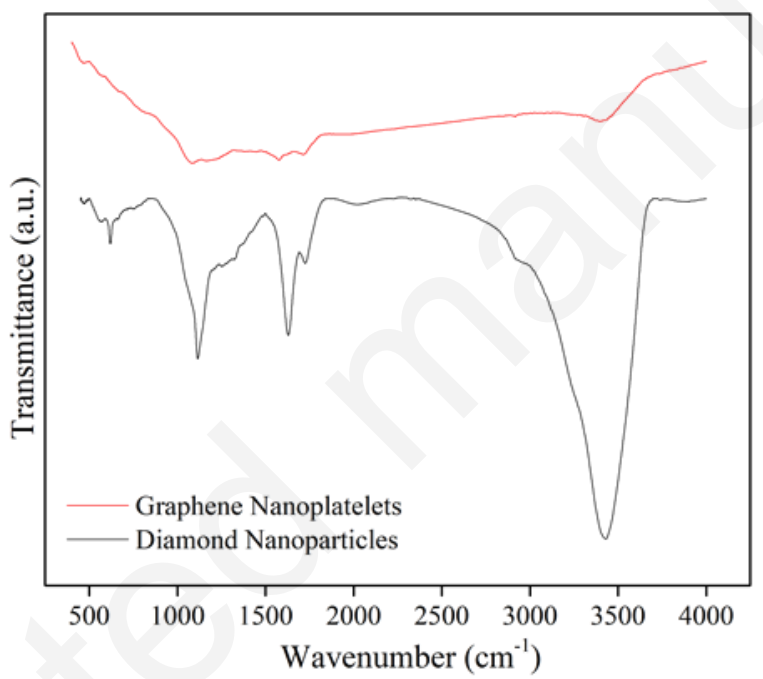

Figure 7: FTIR scans of diamond nanoparticles and graphene nanoplatelets

\subsection{Stability of nanofluids}

Nanofluid stability is a crucial factor in practical applications, and it is directly influenced by the nature and properties of nanomaterial and conventional fluid. The validity and effectivity of a nanosuspension depend on its stability. Therefore, the stability should be evaluated before thermophysical properties measurements or applying it in any heat transfer device. In this research, the two-step method is employed to disperse a hybrid mixture of diamond nanoparticles and graphene nanoplatelets in HRMO. Initially, the samples are prepared using ultrasonication and without surfactant. However, all the nanofluids exhibited very poor stability, and nanomaterial sediment appeared at the bottom of the glass tubes. Then, a new set of samples are prepared using a non-ionic surfactant (Span 85). After a few tests, the optimum mass concentration of hybrid nanomaterial to surfactant (Span85) ratio is fixed at 1:5. In our previous study [44] involving diamond dispersions in a similar type of oil, the optimum concentration of stabilizer was found at 1:7 (diamond:Span85). However, the required surfactant quantity in this research is found to be less due to the presence of graphene nanoplates. Graphene 
diamond nanoparticles with three-dimensional structure (all dimensions are approximately similar) or zero-dimensional (if treated as a point). Muthuraj et al. [68] prepared graphene nanoplatelets dispersions in sunflower oil using 1-hour ultrasonication to stabilize nanofluids without surfactant. In the present investigation, Span 85 provides prolonged stability to hybrid nanosuspensions. Fresh nanofluid samples are prepared with the overmentioned surfactant at five varying concentrations and subjected to static conditions at room temperature (296K). The photographs are taken after five months, and the nanofluids are found to be highly stable without any clear liquid at the top or bottom sediments, shown in Figure 8. Another photograph is taken after nine months of preparation that can be visualized in Figure 8. A visible flocculated-type sediment or unstable formations are observed in all samples after nine months of preparation. The hybrid nanosuspension with a high concentration $(2 \%)$ can be seen intact and dispersed in HRMO after nine months. Based on these results, it can be concluded that the hybrid nanofluids exhibit a minimum of five months stability at static and ambient conditions. Generally, the nanofluids with high nanomaterials concertation exhibit fast sedimentation compared to low concentrations. However, this research shows that the high concentration (2\%) of hybrid nanofluid exhibits prolonged stability than lower concentrations after nine months. This is attributed to the packing effect in particle-liquid suspensions. The high concentration of large dimensional materials such as tubular structures or nano-sheets may behave differently than small dimensional particles. Increasing the concentration of large dimensional nanomaterials in the fluid drastically increase the viscosity due to the packing effect. A further increase in concentration leads to slurry formation until it ceases to flow. Therefore, it is possible that the high concentration of hybrid nanofluid in this research may exhibit packing effect due to the presence of graphene nanoplatelets. Thus, indicating a better stability than lower mass concentrations.
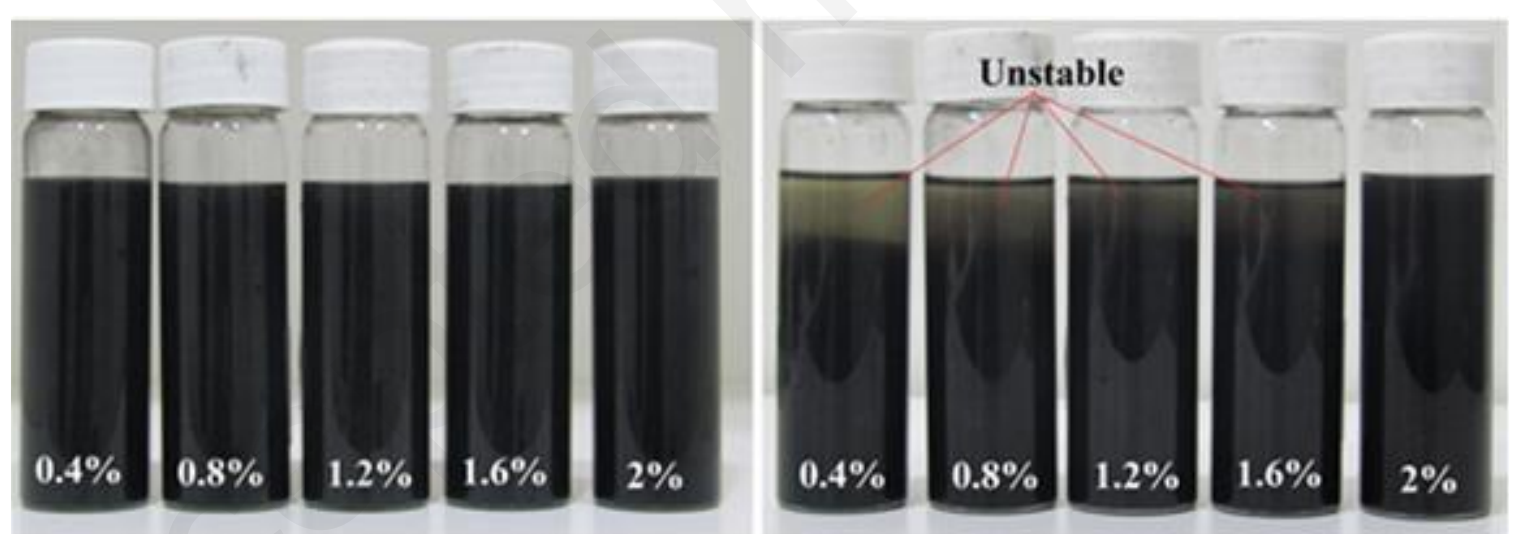

Five months after preparation

Nine months after preparation

Figure 8: Stability evaluation of hybrid nanosuspensions in HRMO after (a) five months and (b) nine months of preparation.

\subsection{Rheology Experimental Measurements}

Fresh samples of hybrid nanosuspensions are subjected to rheology measurements at a wide range of shear rates and temperatures as described previously. The experimental results are analyzed, and the sensitivity of shear rate, temperature, nanomaterial concentration, and surfactant is discussed in the following sub-sections. 


\subsubsection{Flow Behaviour}

443 The flow behavior of hybrid nanofluids is investigated under a shear rate range of 1-2000 s $\mathrm{s}^{-1}$ at five different temperatures. The viscosity profiles of HRMO and hybrid nanofluids (stabilized by Span 85) are presented in Figure 9(a-e). It is observed that all HRMO and all nanofluids exhibit similar viscous behavior regardless of the temperature. The viscosity is decreasing during shear ramp conditions, where a generalized decrease is observed at a low shear rate ranging between $1-100 \mathrm{~s}^{-1}$. The change in viscosity in the range of $100-2000 \mathrm{~s}^{-1}$ is minimal compared to viscous values at a low shear rate. It is found that shear-thinning behavior is gradually disappearing at higher shear rates, and the nanofluid samples are tending towards Newtonian plateau, but still not completely Newtonian at the entire investigated shear range. This decrease in viscosity at increasing shear rate also suggests that the HRMO and hybrid nanofluids exhibit shear-thinning behavior, which is more profound at lower shear rates. Similar behavior was also observed by Krishnakumar et al. [69] in the case of Alumina-ethylene glycol nanofluid. Generally, the flow behaviour of HRMO depends on the chemical constituents in it. The composition, type and nature of long/short hydrocarbon chains representing paraffinic, naphthenic, and aromatic components in the oil may change the molecular thermophysical properties, molecular weight and flow behaviour of HRMOs. In this research, HRMO exhibits shear thinning behaviour and the addition of hybrid nanomaterials in HRMO at varying concentrations does not change the trend of flow behavior.
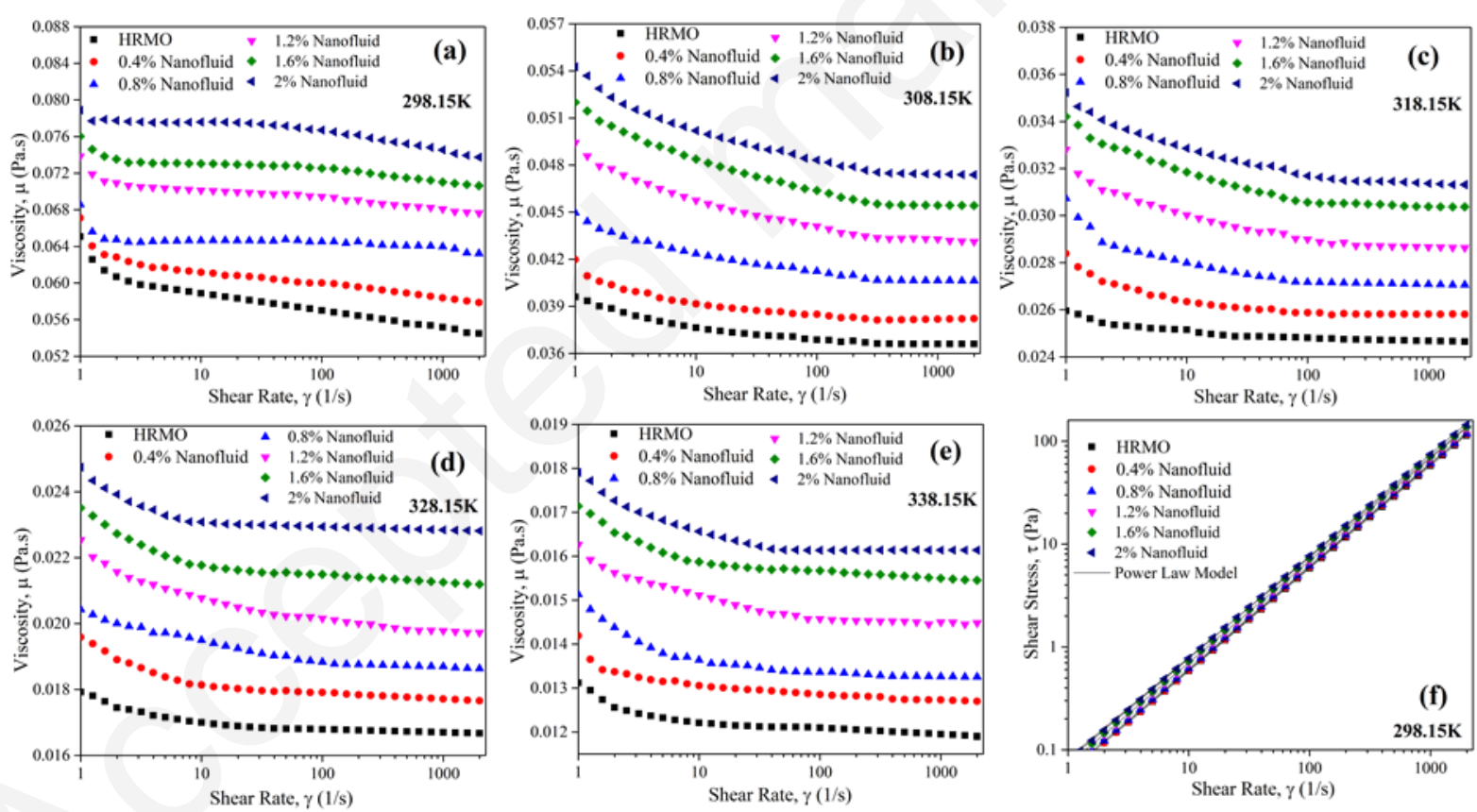

Figure 9: (a-e) The change in viscosity of HRMO and hybrid nanofluids at varying temperatures; (b) Impact of shear stress on the shear behavior, with power-law model fitting.

To further quantify the non-Newtonian character, the experimental shear stress and shear rates are plotted in the logarithmic scale, exemplified in Figure 9(f). The Ostwald-de-Waele relationship is applied to confirm the flow characteristics, given in Eq. (9). This model is also known as the powerlaw model to characterize fluid behavior, where $\tau$ represents shear stress $(\mathrm{Pa}), \gamma$ represents shear rate $\left(\mathrm{s}^{-1}\right), n$ is flow behavior index, or power-law index $(-)$, and $k$ is flow consistency index $\left(\mathrm{Pa} \cdot \mathrm{s}^{\mathrm{n}}\right)$. An 
9(f). Initially, the logarithmic values of shear stress and shear rate are plotted, and the quantities of flow consistency and power-law index are obtained for HRMO and hybrid nanofluids at varying temperatures and mass concentrations. The procedure was previously applied by Cabaleiro et al. [58]. The change in the values of $n$ is the deciding parameter to characterize the nature of nanofluid flow behaviour. If $n=1$, the flow behaviour can be termed as Newtonian. However, if the values of $n$ are $>1$ or $<1$, then the fluid can be categorized non-Newtonian with shear thickening or shear thinning characteristics, respectively. The evaluated values of $n$ and $k$ from the logarithmic relationship between shear stress and shear rate are shown in Figure 10(a) and (b), respectively. HRMO and nanofluids exhibit $n<1$ at all conditions, which confirms the shear-thinning character of fluid. A generic decreasing trend of $n$ is observed by increasing temperature and hybrid nonmaterial mass concertation. This analysis concluded that the hybrid nanofluid flow is shifting away from the Newtonian plateau if the concentration of diamond-graphene nanoplatelets in HRMO is increased. Figure 10(b) presents flow consistency index $k$ at varying temperatures and hybrid nanomaterial concentrations. It is observed that $k$ is increasing with nanofluid mass concertation. However, an inverse relationship is observed with temperature. The increase in $k$ values for hybrid nanofluids can be attributed to the nature of nanomaterials. Generally, the presence of nanomaterials in the fluid resists the shear flow due to nanomaterial geometry and dispersion characteristics. It may lead to an increase in viscosity, and thus, the consistency index is also increased. The reduction in $k$ with enhancing temperature can be attributed to the minimizing interactions among molecules and increasing intermolecular distance leading to lower viscosity and consistency index. Similar behavior for power-law index and flow consistency index was also reported in the literature [70] for hybrid nanofluids containing $\mathrm{Ag}-\mathrm{Fe}_{3} \mathrm{O}_{4}$ dispersions in ethylene glycol/water.

2
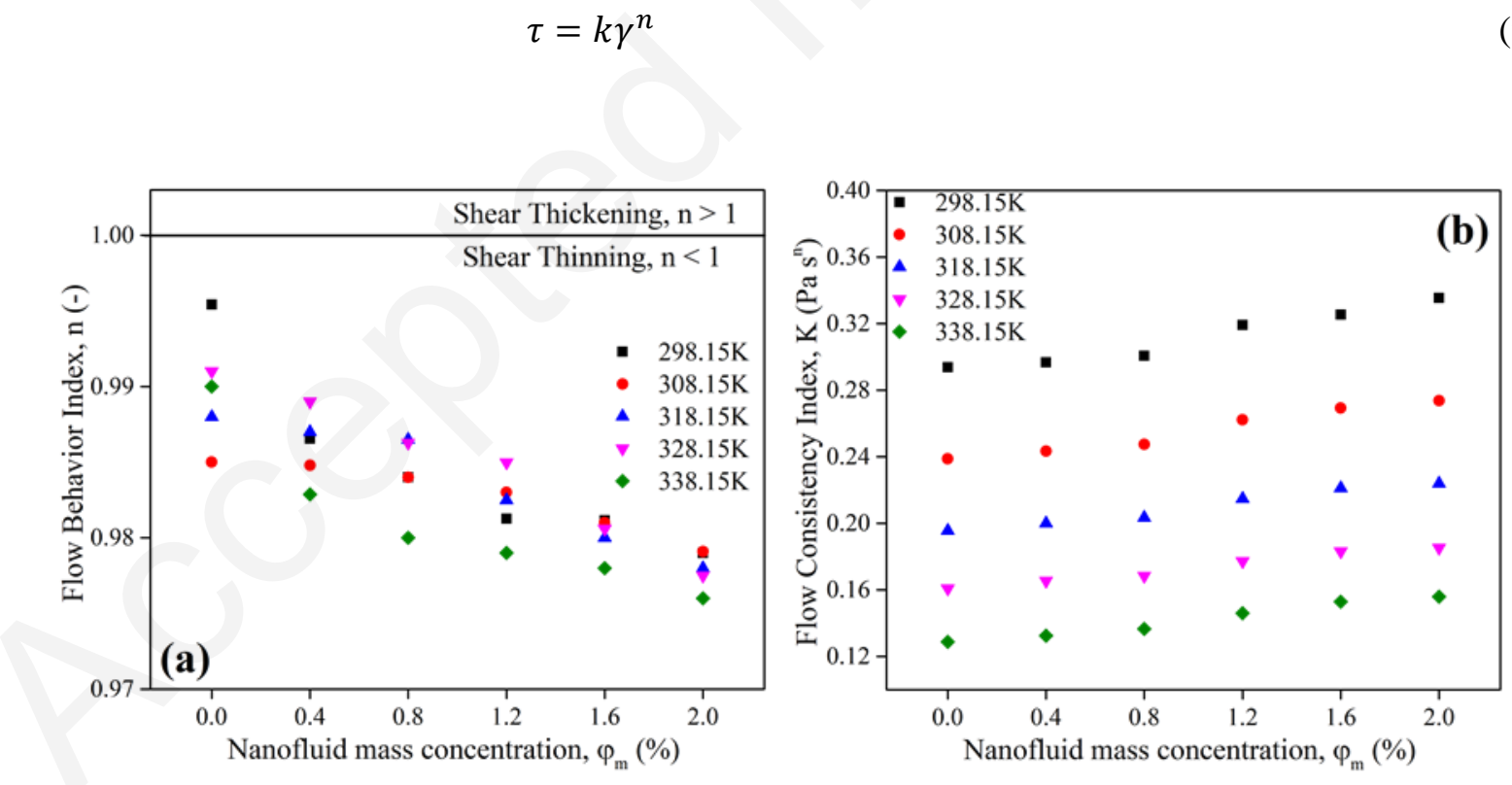

Figure 10: Flow characteristics, (a) flow behavior index, and (b) flow consistency index, of diamondgraphene nanoplatelets at varying temperatures and mass concentrations.

\subsubsection{Impact of Temperature}

Viscosity is a temperature-dependent property, and it is important to understand the flow characteristics of HRMO and hybrid nanofluids at different temperatures for their usage in practical applications. The 
investigations are carried out at five different temperatures. Figure 11 exemplifies the nanosuspension viscosity at a constant shear rate. A typical trend of viscosity-decrement can be seen, which is attributed to intermolecular bond attenuation at high temperatures. An average of $79 \%$ decrement in viscosity is observed from $298.15 \mathrm{~K}$ to $338.15 \mathrm{~K}$. Interestingly, the average viscosity difference between HRMO and hybrid nanofluids becomes smaller with the increase in temperature, evident from Figure 11. This phenomenon can be attributed to the increase in kinematic energy of nanomaterials suspended in the fluid at higher temperatures, which may reduce the resistance to flow and orient the nanomaterials in the direction of flow.

It is a noteworthy fact that the stochastic motion of randomly moving hybrid nanomaterials in a suspension is directly influenced by temperature, which results in a change in the viscous behavior of nanofluid. The presence of graphene nanoplatelets in the suspension along with a spherical-type diamond nanoparticle can have an interesting and different viscous phenomenon compared to mononanomaterial-based nanofluids. Since graphene nanoplatelets have a sheet-type structure and huge dimensions compared to diamond nanoparticles, both nanomaterials may co-exist in a much higher interaction due to entanglement and high surface area. The Brownian motion of nanomaterials increases at elevated temperatures, which directly impacts thermophysical properties [68]. The large dimension of these nanoplatelets may tend them to fold during Brownian motion, which can change the viscous behavior.
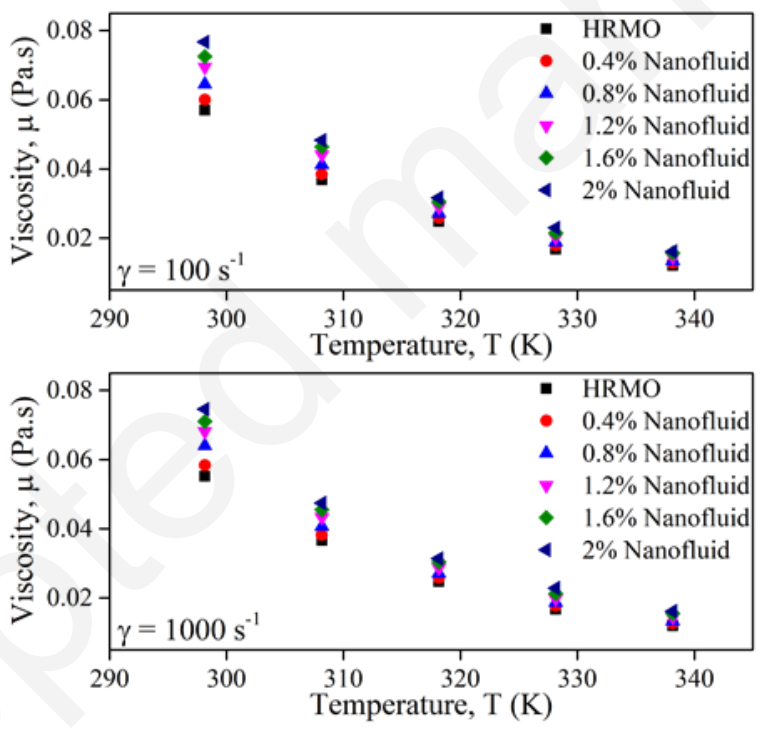

Figure 11: Viscosity of diamond-graphene nanoplatelets hybrid nanofluids at varying temperatures.

Temperature-dependent viscosity can be modeled using the Vogel-Fulcher-Tammann (VFT) model, widely used in the literature [50,51,71]. The model is expressed in Eq. (10).

$$
\mu=\mu_{o} \cdot e^{\frac{A}{T-T_{o}}}
$$

where, $\mu_{o}, A$ and $T_{o}$ are constants and can be adjusted. Viscosity values are not constant, even at higher shear rates. Therefore, fitting parameters are evaluated at four different shear rate conditions, i.e., 100 $\mathrm{s}^{-1}, 500 \mathrm{~s}^{-1}, 1000 \mathrm{~s}^{-1}$, and $2000 \mathrm{~s}^{-1}$. The corresponding values at varying hybrid nanofluid concentrations 
529 and error estimation between experimental and Eq. (10) are tabulated in Table 1. AAD, SSE, and $\mathrm{R}^{2}$ in 530 Table 1 correspond to average absolute deviation (\%), the sum of squared error, and coefficient of 531 determination, respectively. Figure 12 exemplifies and confirms that Eq. (10) can be used to model 532 temperature-dependent viscosity of hybrid nanofluids at varying concentrations.

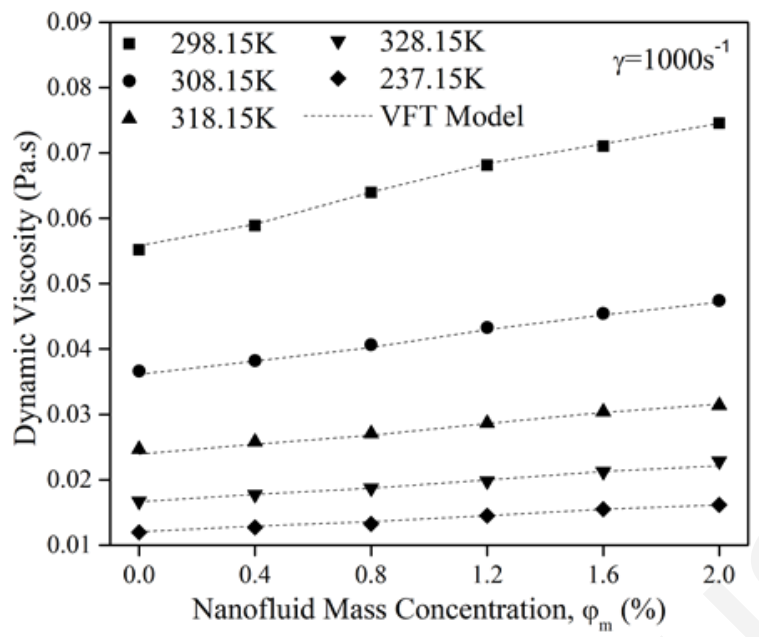

Figure 12: The comparison of experimental data with Eq. (10) at a constant shear rate of $1000 \mathrm{~s}^{-1}$.

Table 1: Adjustable parameters of Eq. (10) and error evaluation at four different shear rates.

\begin{tabular}{|c|c|c|c|c|c|c|}
\hline \multicolumn{7}{|c|}{ Shear Rate $100 \mathrm{~s}^{-1}$} \\
\hline Concentration (\%) & $\mathbf{0}$ & 0.4 & 0.8 & 1.2 & 1.6 & 2 \\
\hline$\mu_{o}(\mathrm{~Pa} \cdot \mathrm{s}) \times 10^{-5}$ & 4.768 & 5.34 & 5.58 & 5.9 & 6.58 & 6.51 \\
\hline $\boldsymbol{A}(\mathbf{K})$ & 1000.64 & 1000.62 & 1000.65 & 1000.66 & 1000.56 & 1000.71 \\
\hline$T_{o}(\mathbf{K})$ & 157.52 & 156.08 & 156.3 & 156.63 & 155.33 & 156.66 \\
\hline AAD $(\%)$ & 0.22 & 0.82 & 0.93 & 0.37 & 0.31 & 0.85 \\
\hline $\mathrm{SSE}(\mathrm{Pa} \cdot \mathrm{s}) \times 10^{-6}$ & 2.95 & 1.39 & 0.58 & 0.32 & 0.28 & 0.58 \\
\hline $\mathbf{R}^{2}(\%)$ & 99.95 & 99.96 & 99.97 & 99.98 & 99.98 & 99.97 \\
\hline \multicolumn{7}{|c|}{ Shear Rate $500 \mathrm{~s}^{-1}$} \\
\hline Concentration (\%) & $\mathbf{0}$ & 0.4 & 0.8 & 1.2 & 1.6 & 2 \\
\hline$\mu_{o}(\mathrm{~Pa} \cdot \mathrm{s}) \times 10^{-5}$ & 4.78 & 5.3 & 5.52 & 5.89 & 6.57 & 6.85 \\
\hline $\boldsymbol{A}(\mathbf{K})$ & 1000.64 & 1000.98 & 1001.01 & 1001.01 & 1000.91 & 996.27 \\
\hline$T_{o}(\mathbf{K})$ & 157.34 & 155.99 & 156.33 & 156.36 & 155.08 & 155.83 \\
\hline AAD (\%) & 0.37 & 1.14 & 0.88 & 0.364 & 0.11 & 0.81 \\
\hline $\mathrm{SSE}(\mathrm{Pa} \cdot \mathrm{s}) \times 10^{-6}$ & 1.39 & 3.07 & 0.3 & 0.12 & 0.54 & 0.51 \\
\hline $\mathbf{R}^{2}(\%)$ & 99.88 & 99.93 & 99.98 & 99.98 & 99.99 & 99.97 \\
\hline \multicolumn{7}{|c|}{ Shear Rate $1000 \mathrm{~s}^{-1}$} \\
\hline Concentration (\%) & $\mathbf{0}$ & 0.4 & 0.8 & 1.2 & 1.6 & 2 \\
\hline$\mu_{o}(\mathrm{~Pa} \cdot \mathbf{s}) \times 10^{-5}$ & 4.78 & 5.46 & 5.62 & 6 & 6.64 & 6.89 \\
\hline$A(\mathbf{K})$ & 1000.62 & 996.27 & 996.47 & 996.47 & 996.69 & 996.65 \\
\hline$T_{o}(\mathbf{K})$ & 157.161 & 155.849 & 156.557 & 156.582 & 155.351 & 155.498 \\
\hline AAD $(\%)$ & 0.274 & 1.38 & 0.917 & 0.456 & 0.264 & 0.849 \\
\hline $\mathrm{SSE}(\mathrm{Pa} \cdot \mathrm{s}) \times 10^{-6}$ & 2.25 & 0.279 & 0.365 & 0.206 & 0.189 & 0.597 \\
\hline $\mathbf{R}^{2}(\%)$ & 99.97 & 99.89 & 99.91 & 99.98 & 99.99 & 99.97 \\
\hline \multicolumn{7}{|c|}{ Shear Rate $2000 \mathrm{~s}^{-1}$} \\
\hline Concentration (\%) & $\mathbf{0}$ & 0.4 & 0.8 & 1.2 & 1.6 & 2 \\
\hline$\mu_{o}(\mathrm{~Pa} \cdot \mathrm{s}) \times 10^{-5}$ & 4.89 & 5.49 & 5.29 & 5.98 & 6.57 & 6.96 \\
\hline $\boldsymbol{A}(\mathbf{K})$ & 1000.56 & 996.65 & 999.09 & 998.38 & 998.31 & 998.67 \\
\hline$T_{o}(\mathbf{K})$ & 156.46 & 155.51 & 157.77 & 156.26 & 155.34 & 154.78 \\
\hline AAD $(\%)$ & 0.39 & 1.62 & 1.1 & 0.52 & 0.42 & 0.93 \\
\hline $\mathrm{SSE}(\mathrm{Pa} \cdot \mathrm{s}) \times 10^{-6}$ & 1.32 & 3.34 & 4.08 & 0.29 & 0.57 & 0.82 \\
\hline $\mathbf{R}^{2}(\%)$ & 99.98 & 99.84 & 99.93 & 99.98 & 99.98 & 99.97 \\
\hline
\end{tabular}




\subsubsection{Impact of Nanomaterial Mass Concentration}

538 The concentration of nanofluids plays a vital role in designing thermal applications. The thermal 539 properties of the fluid can be elevated by increasing the quantity of nanomaterials. However, the 540 viscosity can also shoot up at high concentrations, which may adversely impact on the thermal 541 performance of the system. Therefore, the quantity of nanomaterials in conventional fluid must be 542 optimized. There is a consensus among the reported studies that the viscous parameter is directly 543 proportional to the amount of dispersed nanomaterials in the liquid. In this research, nanofluids are 544 experimentally tested at five varying mass concentrations. Figure 13 represents the percentage increase 545 in viscosity of hybrid nanofluids compared to HRMO at temperatures $298.15 \mathrm{~K}$ and $338.15 \mathrm{~K}$, and shear 546 rates $500 \mathrm{~s}^{-1}$ and $2000 \mathrm{~s}^{-1}$. An increasing trend in hybrid nanofluid viscosity is observed at all 547 investigated conditions. It is observed that the lower mass concentration $(0.4 \%)$ constitutes an average $5486 \%$ enhancement in viscosity. However, the highest mass concentration exhibits an average $35 \%$ 549 elevation in viscosity. Similar trends are observed at different shear rates and temperature conditions for all samples. This increase is attributed to diamond and graphene nanoplatelets in HRMOs that act as a solid particle and sheets-type structure, respectively. It provides extra resistance among the different folds of fluid media layers at the molecular level. This extra resistance results in a reducing flow character and hence, increasing the viscosity of the fluid. It is crucial to mention that two-dimensional nanomaterial under Brownian motion exhibit entanglement behavior. The movement of sheet-type nanomaterials is multi-directional in the fluid medium that can influence the viscosity.

A comparison of this investigation and our previous works [27,29,44,72] involving similar base fluid is presented in Figure 14 to state the position of diamond-graphene nanoplates hybrid nanofluids among mono-nanoparticle based nanofluid systems. It is observed that nanofluids containing MWCNTs in oil [72] have a relatively high increment in viscosity compared to hybrid nanosuspension. A generic comparison of hybrid nanofluids with diamond-oil nanosuspensions [44] suggests minimal difference in viscosity enhancement. However, oil-based nanosuspension containing functionalized metallic oxide nanoparticles constitutes lower viscosity enhancement than hybrid nanofluids under investigation. 

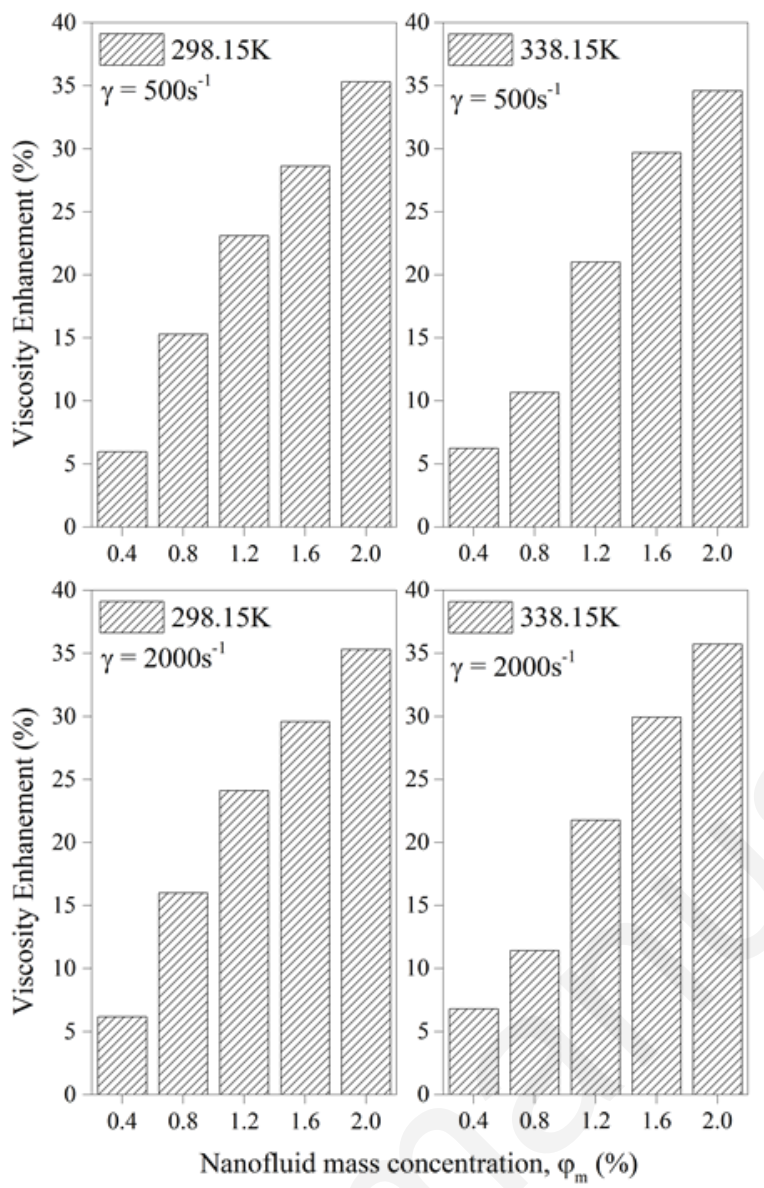

Figure 13: Impact of diamond-graphene nanoplatelets hybrid nanofluid concentration.

\subsubsection{Impact of Surfactant}

567 The addition of surfactants can alter the rheology of nanofluids [47]. In this research, hybrid nanofluids

568 are prepared using a non-ionic surfactant, i.e., Span 85. The mass concentration of hybrid nanomaterial

569 to surfactant (Span85) ratio is fixed at 1:5. A new sample is prepared with HRMO mix with Span 85

570 and without hybrid nanomaterial to analyze the impact of surfactant. The surfactant quantity in the new sample is set equivalent to $2 \%$ nanofluid but without hybrid nanomaterials. This sample is named HRMO+Span85(1:5). The comparative results of pure HRMO, HRMO+Span85(1:5), and 2\% nanofluid are compared in Figure 15 at two different shear rates. An interesting phenomenon is observed, HRMO viscosity is slightly increased by adding surfactant alone. Similar behavior is observed at all temperature conditions. Relative viscosities for HRMO+Span85(1:5) and 2\% nanofluid compared to HRMO are evaluated and presented in Figure 15(b). It is observed that HRMO+Span85(1:5) exhibits an enhancement in the range of $7.8 \%$ to $14.9 \%$ at varying temperatures, where $14.9 \%$ is observed that $338.15 \mathrm{~K}$. However, the viscosity enhancement for $2 \%$ nanofluid is in the range of $27-35 \%$, where the maximum increase is found at $338.15 \mathrm{~K}$. It can be concluded from this comparative study that the quantity of surfactant directly influences the viscous properties of hybrid nanofluids by a wide margin. 


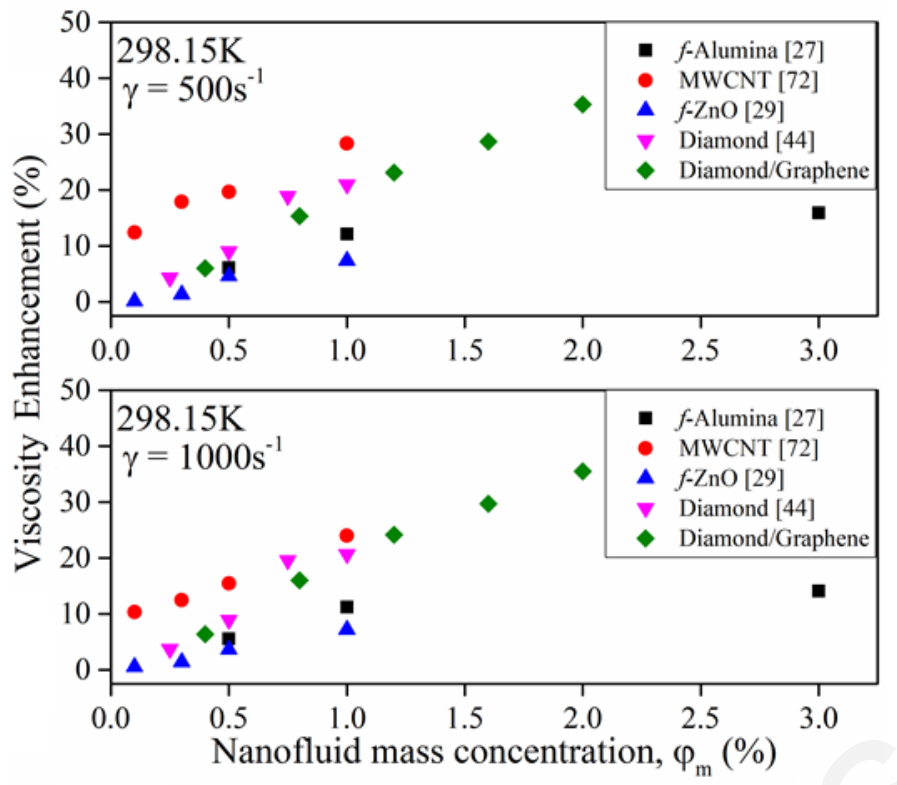

Figure 14: Comparative analysis of viscosity enhancement of hybrid nanofluids compared to the literature $[27,29,44,72]$ using similar base fluid.
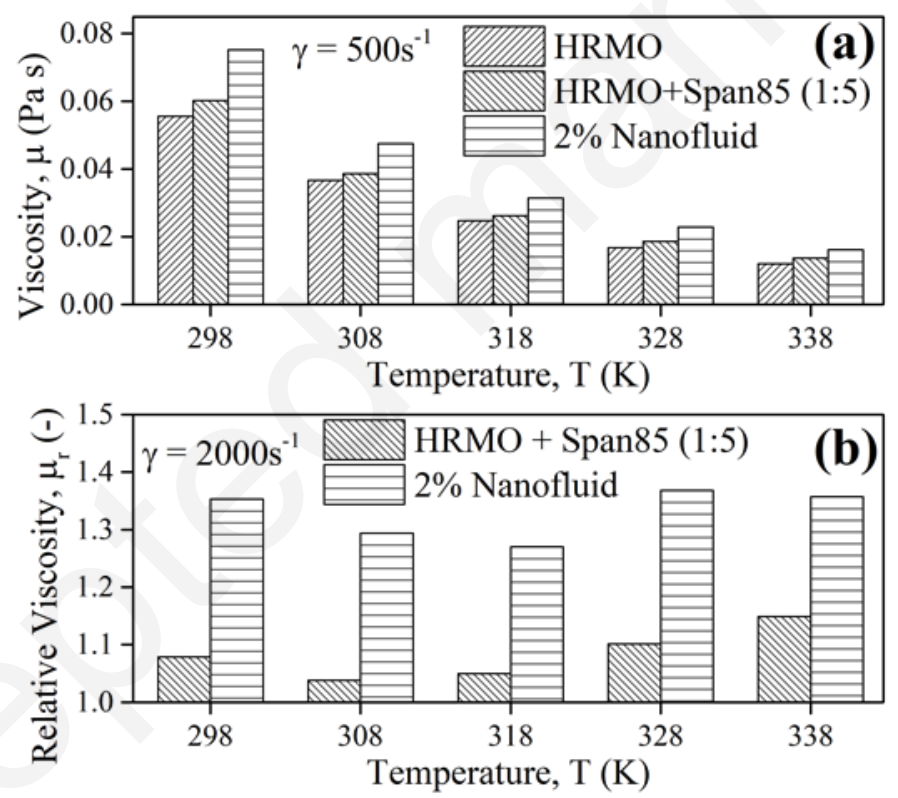

Figure 15: Influence of surfactant on the viscosity of HRMO and nanofluid at varying temperatures.

\subsection{Two-Variable Correlation}

A generalized two-variable correlation is developed to express viscosity of diamond-graphene nanoplatelets based hybrid nanosuspension as a function of temperature and hybrid nanomaterial volumetric concertation. Eq. 1 is utilized to covert mass concentration to volumetric concentration. The correlation equation is given in Eq. (11). The generic form of this correlation is taken from the studies performed by Vallejo et al. [50,51]. The correlation is applied to four different shear rates, i.e., $100 \mathrm{~s}^{-1}$, $500 \mathrm{~s}^{-1}, 1000 \mathrm{~s}^{-1}$, and $2000 \mathrm{~s}^{-1}$. The parity plots are presented in Figure 16, and the fitting parameters, along with the error estimations, are tabulated in Table 2. It is found that the predicted values from Eq. (11) are under $\pm 5 \%$ mean absolute error. The new coefficients of adjustable parameters considering 
temperature and concentration are presented in Table 2. Here, $\mu_{o}, A$ and $T_{o}$ are fixed for the base fluid and can be referred to Table 1.

$$
\mu=\mu_{o} \cdot e^{\frac{A}{T-T_{o}}}+B \varphi_{v} \cdot e^{c / T}-D \varphi_{v}^{2}
$$
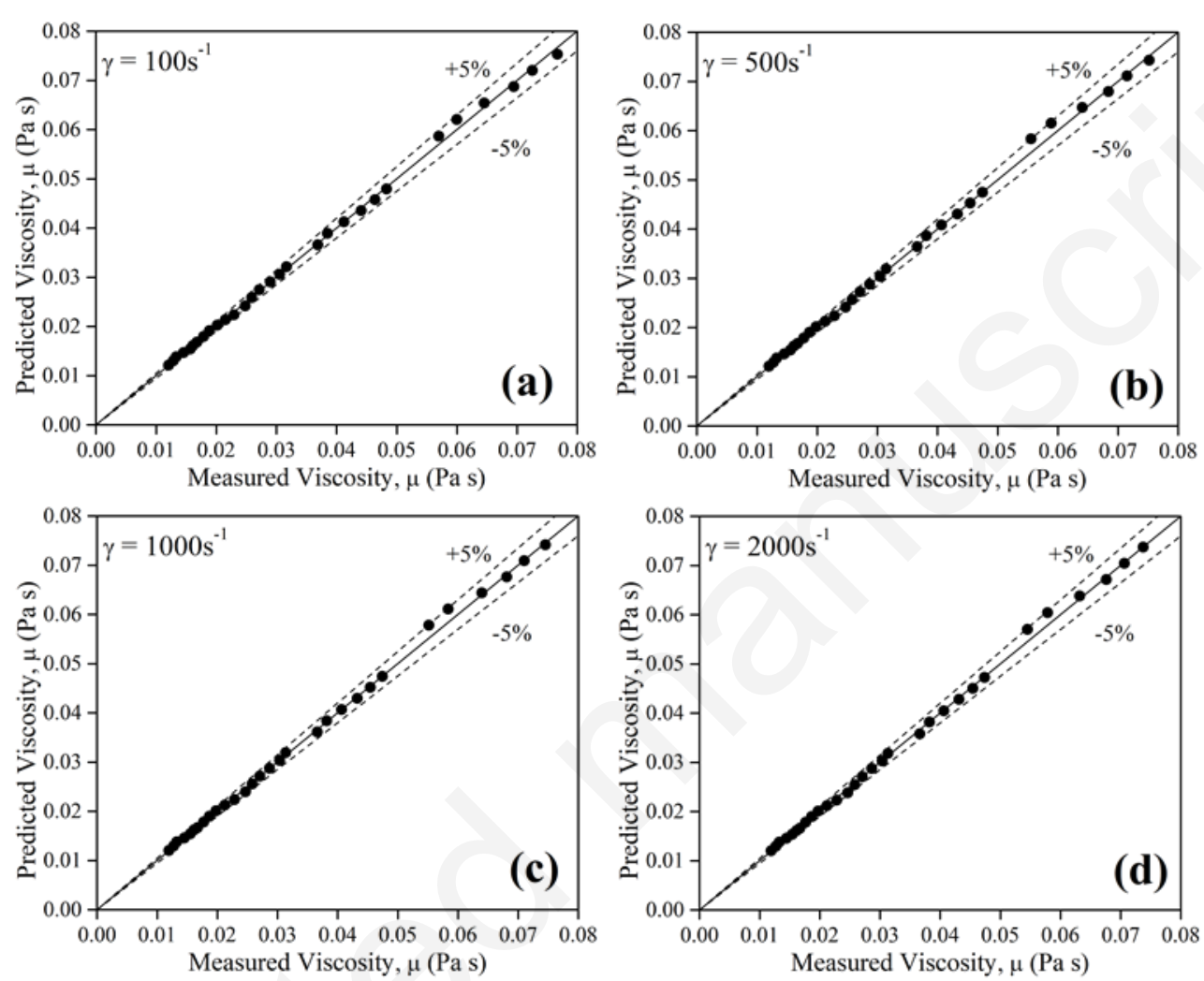

Figure 16: Parity plots for the comparative analysis of experimental data and Eq. (11) at (a) $100 \mathrm{~s}^{-1}$, (b) $500 \mathrm{~s}^{-1}$, (c) $1000 \mathrm{~s}^{-1}$ and (d) $2000 \mathrm{~s}^{-1}$.

Table 2: Adjustable parameters of Eq. (11) and error evaluation at four different shear rates.

\begin{tabular}{lcccc}
\hline Shear rate $\left(\mathbf{s}^{-\mathbf{1}}\right)$ & $\mathbf{1 0 0}$ & $\mathbf{5 0 0}$ & $\mathbf{1 0 0 0}$ & $\mathbf{2 0 0 0}$ \\
\hline $\boldsymbol{B}(\mathbf{P a} \cdot \mathbf{s}) \times \mathbf{1 0}^{-7}$ & 3.343 & 3.343 & 3.343 & 3.343 \\
$\boldsymbol{C}(\mathbf{K})$ & 3246.482 & 3227.738 & 3235.095 & 3246.609 \\
$\boldsymbol{D}(\mathbf{P a} \cdot \mathbf{s}) \times \mathbf{1 0}^{-4}$ & 6.357 & 2.155 & 2.616 & 5.323 \\
$\mathbf{A A D}(\%)$ & 1.17 & 1.23 & 1.16 & 1.28 \\
$\mathbf{S S E}(\mathbf{P a} \cdot \mathbf{s}) \times \mathbf{1 0} \mathbf{1 0}^{-5}$ & 1.3 & 1.81 & 1.69 & 1.65 \\
$\mathbf{R}^{\mathbf{2}}(\boldsymbol{\%})$ & 99.88 & 99.84 & 99.85 & 99.85 \\
\hline
\end{tabular}

\subsection{Predictions via Machine Learning Algorithms}

Three different algorithms are applied to predict the viscosity of hybrid nanofluids as a function of three input variables (temperature, mass concentration, and shear rate). The comparative error matrix for these three algorithms is compared in Table 3. At first, the ANN algorithm is trained iteratively to select the best possible hyperparameters such as the number of neurons, number of hidden layers, activation 
function, number of iterations, and learning rate of the algorithm. A grid search is performed within a range of parameters to evaluate the optimum parameter. Rectified Linear Unit (ReLU) is set as the activation function with five number of hidden layers. The optimized architecture of ANN is found at five neurons at a learning rate of 0.01, as shown in Figure 17. Xavier initialization is used to evenly initiate the weights to avoid local minima and vanishing gradient problem. Gradient descent is used as an optimization algorithm, and the algorithm performance on train and test datasets are monitored to prevent overfitting. An optimum number of neurons are selected at 5 in each layer to achieve a balanced trade-off between the error metrics utilized in this study. The train and test data are plotted in Figure 18(a) and (b), respectively. A good agreement between the experimental viscosity and ANN predictions 619 are observed.

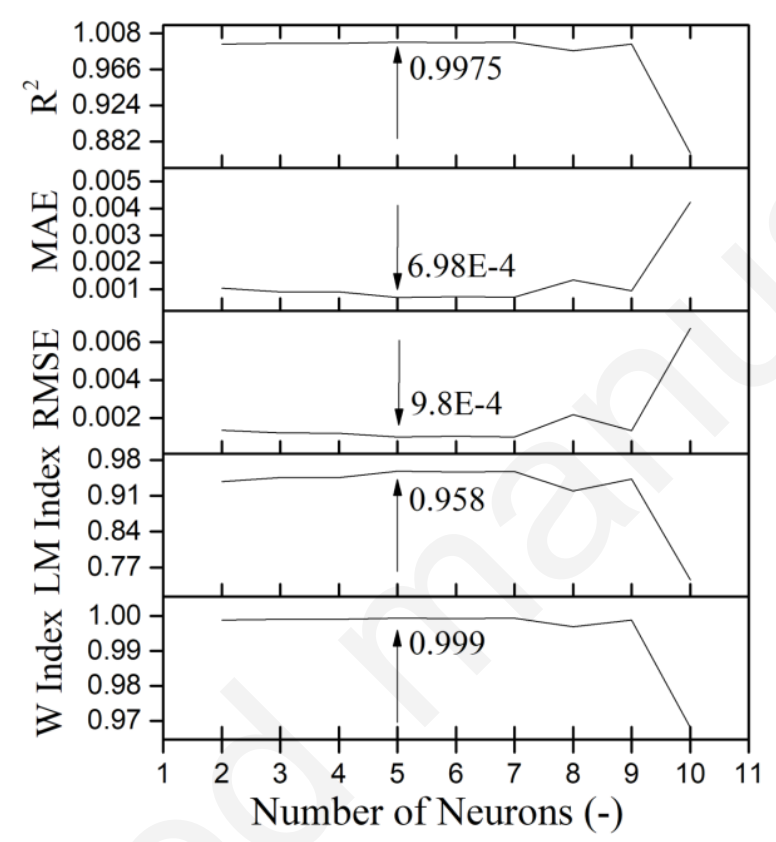

620
Figure 17: Error analysis to find an optimum number of neurons for ANN predictions of hybrid nanofluid viscosity.

GBM is applied as a second algorithm to predict hybrid nanofluid viscosity. Figure 18(c) and (d) presents the observed and the predicted values for the train and test dataset for GBM. The coefficient of determination $\mathrm{R}^{2}$ is observed to be 0.99 for both datasets, and other error metrics are monitored lower, as shown in Table 3. The learning rate for GBM is set at 0.5 with a maximum depth of 50 . The number of estimators is selected as 10 with a loss function of mean squared error. All hyperparameters are iteratively chosen for optimum performance. The $\mathrm{R}^{2}$ for the train and testing data exhibit a 0.99 value, while other error metrics for both datasets are relatively similar. It shows that GBM can predict the viscosity of nanofluids with high precision. It is observed from Figure 18(c) and (d) that some predicted values deviate from the reference equality line at approximately $0.05 \mathrm{~Pa} \cdot \mathrm{s}$ and $0.07 \mathrm{~Pa}$.s. However, a dense data cloud is observed at the reference equality line below $0.05 \mathrm{~Pa} \cdot \mathrm{s}$.

The predictions for RF algorithms for train and test datasets are plotted in Figure 18(e) and (f). An excellent prediction pattern is observed in the case of RF algorithm. The hyperparameters for RF are iteratively selected. The number of estimators is 10 , and the minimum leaf split is set at 2 . The performance of both data segments is almost similar, which concludes that RF can simulate the 

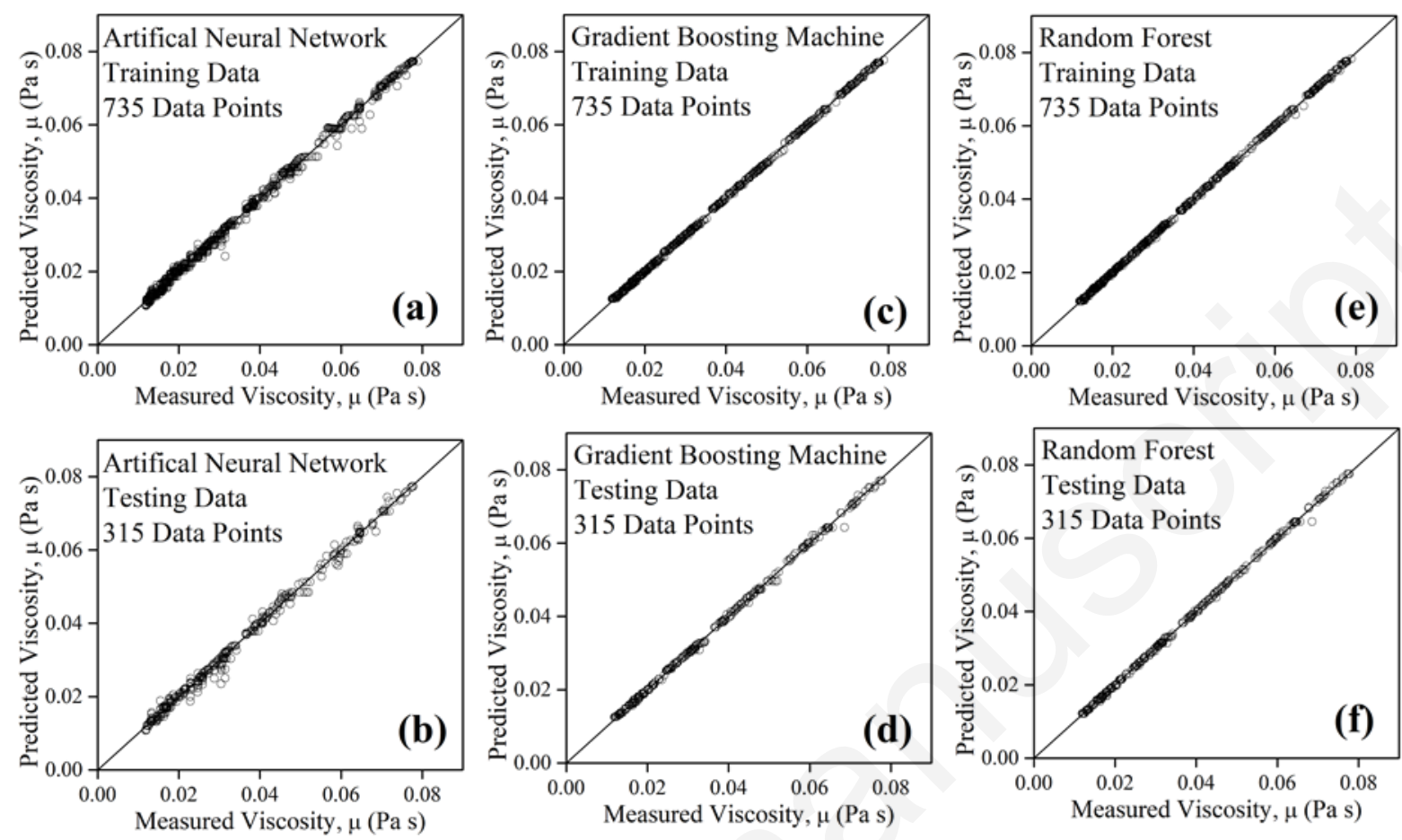

Figure 18: Parity plots for predictions of training and testing data using (a, b) ANN, (c, d) GBM, and (e, f) RF algorithms.

642 The evaluated error for ANN, GBM, and RF is summarized in Table 3. It can be deduced from the 643 comparative error matrix that the performance of all three algorithms on both testing and training is very similar. It concludes the potential of machine learning algorithms in predicting the viscosity of hybrid nanofluids based on multi-input parameters. It is found that ANN predictions exhibit slight deviations in training and testing data, while GBM and RF do not show such considerable deviations. Overall, RF algorithm outperforms all other algorithms and is the suitable machine learning method for the dataset obtained in this investigation.

Table 3: A comparative error analysis for machine learning algorithms

\begin{tabular}{ccccccc}
\hline \multirow{2}{*}{ Errors } & \multicolumn{2}{c}{ ANN } & \multicolumn{2}{c}{ RF } & \multicolumn{2}{c}{ GBM } \\
\cline { 2 - 7 } & Train & Test & Train & Test & Train & Test \\
\hline $\mathbf{R}^{\mathbf{2}}$ & 0.9983 & 0.9976 & 0.9998 & 0.9993 & 0.9997 & 0.9991 \\
MAE & 0.0005 & 0.0006 & 0.0001 & 0.0002 & 0.0002 & 0.0003 \\
RMSE & 0.0007 & 0.0008 & 0.0002 & 0.0004 & 0.0003 & 0.0005 \\
$\mathbf{E}_{\mathbf{L}, \mathbf{M}}$ & 0.9656 & 0.9581 & 0.9891 & 0.9819 & 0.9849 & 0.9765 \\
$\mathbf{I}_{\mathbf{A}}$ & 0.9995 & 0.9994 & 0.9999 & 0.9998 & 0.9999 & 0.9997 \\
\hline
\end{tabular}

650 
This research involves an experimental evaluation of rheological parameters of hybrid nanosuspensions containing diamond nanoparticles and graphene nanoplatelets (1:1) in highly refined mineral oil (HRMO). The investigation is performed at varying mass concentrations (0-2 mass $\%)$ and temperatures (298.15-338.15K). The nanofluids are prepared using the two-step method involving ultrasonication and surfactant addition. Characterizations are performed for nanomaterials, which confirm the primary size, elemental composition, and high purity. The stability of nanosuspensions is evaluated for five months, and no sediment is observed. The rheological characteristics conclude that a shear-thinning non-Newtonian behavior is found, and the flow behavior index for all samples at varying temperatures is $<1$. The non-Newtonian behavior can be well-described by the Ostwald-de-Waele model. The sensitivity of temperature on viscous behavior shows an average of $79 \%$ decrement in viscosity from $298.15 \mathrm{~K}$ to $338.15 \mathrm{~K}$. VFT model is used to express temperature-dependent viscosity of HRMO and hybrid nanofluids, and fitting parameters are presented. A maximum of $35 \%$ increase in viscosity of hybrid nanosuspension is observed at the highest concentration of $2 \%$. It is also observed that the addition of Span 85 in HRMO-based nanofluids increases the overall viscosity by a maximum of $14 \%$. A generalized two-variable correlation is used to express viscosity as a function of temperature and hybrid nanofluid concentration with an excellent agreement. Finally, three machine learning algorithms are finally applied to predict the viscosity of hybrid nanosuspensions based on three input parameters. RF algorithm shows excellent predictions compared to GBM and ANN, which shows the potential of artificial intelligence in predicting the thermophysical properties of nanosuspensions.

A complete understanding of complex fluid's rheological behaviour is extremely intricate due to the known and unknown phenomenon occurring at the molecular level, such as this investigation. This research is focused on the rheology of stabilized Diamond-Graphene nanoplatelets in HRMO, which has significant potential in opening new horizons in the field of nanofluids, especially complex systems having two nanomaterials with different structures and properties. The authors intend to highlight that the increase in the hybrid nanofluids' viscosity might not be suitable for an ideal heat transfer fluid. Therefore, a detailed experimental analysis should be performed on other thermophysical properties to see a complete narrative of heat transfer and other applications. The authors propose to expand the research towards a detailed experimental architecture, including other stability methods and thermophysical properties. This research can be counted as a further step towards long-term stability and hybrid nanofluid-based structure-condition-property relationship.

\section{Nomenclature}

$\begin{array}{lll}683 & A & \text { Adjustable parameter in Eq. } 10(\mathrm{~K}) \\ 684 & B & \text { Adjustable parameter in Eq. 11 (Pa.s) } \\ 685 & C & \text { Adjustable parameter in Eq. 11 (K) } \\ 686 & D & \text { Adjustable parameter in Eq. 11 (Pa.s) } \\ 687 & E_{L M} & \text { Legate and McCabe Index, LM Index (-) } \\ 688 & I_{A} & \text { Willmot index of agreement, W Index (-) } \\ 689 & k & \left.\text { Flow consistency index (Pa. } \mathrm{s}^{\mathrm{n}}\right) \\ 690 & n & \text { Flow behavior index (-) } \\ 691 & N & \text { Number of observations in Eq. (4)-(8) } \\ 692 & R^{2} & \text { Coefficient of determination (-) } \\ 693 & T & \text { Temperature (K) } \\ 694 & T_{o} & \text { Adjustable parameter in Eq. 10 (K) } \\ 695 & x & \text { Input data value in Eq. (2) and (3) } \\ 696 & y_{i} & \text { Given data point in Eq. (4)-(8) } \\ 697 & \hat{y}_{i} & \text { Predicted values in Eq. (4)-(8) }\end{array}$


$698 \quad \bar{y}_{i} \quad$ Mean of the given values in Eq. (4)-(8)

699 Greek Symbols

$700 \varphi \quad$ Nanomaterial concentration (\%)

$701 \rho \quad$ Density $\left(\mathrm{kg} / \mathrm{m}^{3}\right)$

$702 \gamma \quad$ Shear rate $(1 / \mathrm{s})$

$703 \tau \quad$ Shear stress $(\mathrm{Pa})$

$704 \mu \quad$ viscosity (Pa.s)

$705 \mu_{o} \quad$ Adjustable parameter in Eq. $10(\mathrm{~Pa} \cdot \mathrm{s})$

$706 \mu_{r} \quad$ Relative viscosity (-)

707 Abbreviations

708 AAD Average Absolute Deviation

709 ANN Artificial Neural Network

710 GBM Gradient Boosting Machine

711 RF Random Forest

712 HRMO Highly Refined Mineral Oils

713 EOR Enhanced Oil Recovery

714 PSO Particle Swarm Optimization

715 RBF Radial Basis Function

716 LSSVM Least-square Support Vector Machine

717 VFT Vogel-Fulcher-Tammann Model

718 RMSE Root Mean Square Error

719 MAE Mean Absolute Error

720 SSE Sum of Squared Error

721 Subscripts

$722 \quad n p \quad$ Nanoparticle

723 bf Basefluid

$724 v \quad$ Volume

$725 \quad m \quad$ Mass

726 std Standard deviation of input data in Eq. (2) and (3)

727 Scale Scaled input data in Eq. (2) and (3)

$728 \mathrm{~min}$ Minimum value of input data in Eq. (2) and (3)

$729 \max$ Maximum value of input data in Eq. (2) and (3)

730

\section{Authorship Contribution Statement}

732 SU Ilyas: Conceptualization, Methodology, Validation, Formal analysis, Investigation, Writing -

733 Original Draft. S Ridha: Investigation, Resources, Writing - Review \& Editing, Project administration,

734 Funding acquisition. S Sardar: Validation, Formal analysis, Investigation, Writing - Original Draft. P

735 Estellé: Conceptualization, Methodology, Investigation, Writing - Review \& Editing. A Kumar:

736 Software, Formal analysis, Writing - Original Draft. R Pendyala: Conceptualization, Methodology,

737 Resources, Writing - Review \& Editing.

\section{Declaration of Competing Interests}

739 The authors declare that they have no known competing financial interests or personal relationships

740 that could have appeared to influence the work reported in this paper.

\section{Acknowledgment}


This work is supported by the Institute of Hydrocarbon Recovery at Universiti Teknologi PETRONAS. The financial assistance is provided by Yayasan UTP (Grant No. YUTP 015LC0-101).

\section{References}

[1] R. Taylor, S. Coulombe, T. Otanicar, P. Phelan, A. Gunawan, W. Lv, G. Rosengarten, R. Prasher, H. Tyagi, Small particles, big impacts: A review of the diverse applications of nanofluids, J. Appl. Phys. 113 (2013) 011301. doi:10.1063/1.4754271.

[2] K. Khanafer, K. Vafai, A review on the applications of nanofluids in solar energy field, Renew. Energy. 123 (2018) 398-406. doi:10.1016/j.renene.2018.01.097.

[3] M.H. Buschmann, NANOUPTAKE - An European network on nanofluid research, in: 2018. doi:10.14311/tpfm.2018.004.

[4] D. Amin, R. Walvekar, M. Khalid, M. Vaka, N.M. Mubarak, T.C.S.M. Gupta, Recent Progress and Challenges in Transformer Oil Nanofluid Development: A Review on Thermal and Electrical Properties, IEEE Access. 7 (2019) 151422-151438. doi:10.1109/ACCESS.2019.2946633.

[5] A. Asadi, S. Aberoumand, A. Moradikazerouni, F. Pourfattah, G. Żyła, P. Estellé, O. Mahian, S. Wongwises, H.M. Nguyen, A. Arabkoohsar, Recent advances in preparation methods and thermophysical properties of oil-based nanofluids: A state-of-the-art review, Powder Technol. 352 (2019) 209-226. doi:10.1016/j.powtec.2019.04.054.

[6] J. Fal, O. Mahian, G. Żyła, Nanofluids in the Service of High Voltage Transformers: Breakdown Properties of Transformer Oils with Nanoparticles, a Review, Energies. 11 (2018) 2942. doi:10.3390/en11112942.

[7] B. Peng, L. Zhang, J. Luo, P. Wang, B. Ding, M. Zeng, Z. Cheng, A review of nanomaterials for nanofluid enhanced oil recovery, RSC Adv. (2017). doi:10.1039/c7ra05592g.

[8] N.A.C. Sidik, H.A. Mohammed, O.A. Alawi, S. Samion, A review on preparation methods and challenges of nanofluids, Int. Commun. Heat Mass Transf. 54 (2014) 115-125. doi:10.1016/j.icheatmasstransfer.2014.03.002.

[9] R. Saidur, K.Y. Leong, H.A. Mohammed, A review on applications and challenges of nanofluids, Renew. Sustain. Energy Rev. 15 (2011) 1646-1668. doi:10.1016/j.rser.2010.11.035.

[10] O. Mahian, A. Kianifar, S.A. Kalogirou, I. Pop, S. Wongwises, A review of the applications of nanofluids in solar energy, Int. J. Heat Mass Transf. 57 (2013) 582-594. doi:10.1016/j.ijheatmasstransfer.2012.10.037.

[11] X. Cui, C. Li, Y. Zhang, D. Jia, Y. Zhao, R. Li, H. Cao, Tribological properties under the grinding wheel and workpiece interface by using graphene nanofluid lubricant, Int. J. Adv. Manuf. Technol. 104 (2019) 3943-3958. doi:10.1007/s00170-019-04129-8.

[12] H. Singh, V.S. Sharma, S. Singh, M. Dogra, Nanofluids assisted environmental friendly lubricating strategies for the surface grinding of titanium alloy: Ti6Al4V-ELI, J. Manuf. Process. 39 (2019) 241-249. doi:10.1016/j.jmapro.2019.02.004.

[13] G. Żyła, J. Fal, P. Estellé, Thermophysical and dielectric profiles of ethylene glycol based titanium nitride (TiN-EG) nanofluids with various size of particles, Int. J. Heat Mass Transf. 113 (2017) 1189-1199. doi:10.1016/j.ijheatmasstransfer.2017.06.032.

[14] G. Żyła, J.P. Vallejo, J. Fal, L. Lugo, Nanodiamonds - Ethylene Glycol nanofluids: Experimental investigation of fundamental physical properties, Int. J. Heat Mass Transf. 121 (2018) 1201-1213. doi:10.1016/j.ijheatmasstransfer.2018.01.073.

[15] G. Żyła, Nanofluids containing low fraction of carbon black nanoparticles in ethylene glycol: An experimental study on their rheological properties, J. Mol. Liq. 297 (2020) 111732. doi:10.1016/j.molliq.2019.111732.

[16] S. Zeinali Heris, M.A. Razbani, P. Estellé, O. Mahian, Rheological Behavior of Zinc-Oxide Nanolubricants, J. Dispers. Sci. Technol. (2015). doi:10.1080/01932691.2014.945595.

[17] N.A.C. Sidik, I.M. Adamu, M.M. Jamil, G.H.R. Kefayati, R. Mamat, G. Najafi, Recent progress on hybrid nanofluids in heat transfer applications: A comprehensive review, Int. Commun. Heat Mass Transf. 78 (2016) 68-79. doi:10.1016/j.icheatmasstransfer.2016.08.019.

[18] N.A. Che Sidik, M. Mahmud Jamil, W.M.A. Aziz Japar, I. Muhammad Adamu, A review on 
preparation methods, stability and applications of hybrid nanofluids, Renew. Sustain. Energy Rev. 80 (2017) 1112-1122. doi:10.1016/j.rser.2017.05.221.

[19] M.H. Ahmadi, A. Mirlohi, M. Alhuyi Nazari, R. Ghasempour, A review of thermal conductivity of various nanofluids, J. Mol. Liq. 265 (2018) 181-188. doi:10.1016/j.molliq.2018.05.124.

[20] J.A. Ranga Babu, K.K. Kumar, S. Srinivasa Rao, State-of-art review on hybrid nanofluids, Renew. Sustain. Energy Rev. 77 (2017) 551-565. doi:10.1016/j.rser.2017.04.040.

[21] A. Asadi, I.M. Alarifi, L.K. Foong, An experimental study on characterization, stability and dynamic viscosity of CuO-TiO2/water hybrid nanofluid, J. Mol. Liq. 307 (2020) 112987. doi:10.1016/j.molliq.2020.112987.

[22] S.-R. Yan, R. Kalbasi, Q. Nguyen, A. Karimipour, Rheological behavior of hybrid MWCNTsTiO2/EG nanofluid: A comprehensive modeling and experimental study, J. Mol. Liq. 308 (2020) 113058. doi:10.1016/j.molliq.2020.113058.

[23] M. Afrand, K. Nazari Najafabadi, M. Akbari, Effects of temperature and solid volume fraction on viscosity of SiO2-MWCNTs/SAE40 hybrid nanofluid as a coolant and lubricant in heat engines, Appl. Therm. Eng. (2016). doi:10.1016/j.applthermaleng.2016.04.002.

[24] S.O. Giwa, M. Sharifpur, J.P. Meyer, S. Wongwises, O. Mahian, Experimental measurement of viscosity and electrical conductivity of water-based $\gamma$-A12O3/MWCNT hybrid nanofluids with various particle mass ratios, J. Therm. Anal. Calorim. (2020). doi:10.1007/s10973-020-100411.

[25] Z. Tian, S. Rostami, R. Taherialekouhi, A. Karimipour, A. Moradikazerouni, H. Yarmand, N.W.B.M. Zulkifli, Prediction of rheological behavior of a new hybrid nanofluid consists of copper oxide and multi wall carbon nanotubes suspended in a mixture of water and ethylene glycol using curve-fitting on experimental data, Phys. A Stat. Mech. Its Appl. 549 (2020) 124101. doi:10.1016/j.physa.2019.124101.

[26] I.M. Alarifi, A.B. Alkouh, V. Ali, H.M. Nguyen, A. Asadi, On the rheological properties of MWCNT-TiO2/oil hybrid nanofluid: An experimental investigation on the effects of shear rate, temperature, and solid concentration of nanoparticles, Powder Technol. 355 (2019) 157-162. doi:10.1016/j.powtec.2019.07.039.

[27] S.U. Ilyas, R. Pendyala, M. Narahari, L. Susin, Stability, rheology and thermal analysis of functionalized alumina- thermal oil-based nanofluids for advanced cooling systems, Energy Convers. Manag. 142 (2017) 215-229. doi:10.1016/j.enconman.2017.01.079.

[28] G.M. Moldoveanu, A.A. Minea, M. Iacob, C. Ibanescu, M. Danu, Experimental study on viscosity of stabilized $\mathrm{Al} 2 \mathrm{O} 3$, TiO 2 nanofluids and their hybrid, Thermochim. Acta. 659 (2018) 203-212. doi:10.1016/j.tca.2017.12.008.

[29] S.U. Ilyas, M. Narahari, J.T.Y. Theng, R. Pendyala, Experimental evaluation of dispersion behavior, rheology and thermal analysis of functionalized zinc oxide-paraffin oil nanofluids, J. Mol. Liq. (2019). doi:10.1016/j.molliq.2019.111613.

[30] A. Banisharif, M. Aghajani, S. Van Vaerenbergh, P. Estellé, A. Rashidi, Thermophysical properties of water ethylene glycol (WEG) mixture-based $\mathrm{Fe} 3 \mathrm{O} 4$ nanofluids at low concentration and temperature, J. Mol. Liq. $302 \quad$ (2020) 112606. doi:10.1016/j.molliq.2020.112606.

[31] M.H. Ahmadi, B. Mohseni-Gharyehsafa, M. Ghazvini, M. Goodarzi, R.D. Jilte, R. Kumar, Comparing various machine learning approaches in modeling the dynamic viscosity of $\mathrm{CuO} /$ water nanofluid, J. Therm. Anal. Calorim. 139 (2020) 2585-2599. doi:10.1007/s10973019-08762-z.

[32] M. Ramezanizadeh, M.H. Ahmadi, M.A. Nazari, M. Sadeghzadeh, L. Chen, A review on the utilized machine learning approaches for modeling the dynamic viscosity of nanofluids, Renew. Sustain. Energy Rev. 114 (2019) 109345. doi:10.1016/j.rser.2019.109345.

[33] M. Vakili, S. Khosrojerdi, P. Aghajannezhad, M. Yahyaei, A hybrid artificial neural networkgenetic algorithm modeling approach for viscosity estimation of graphene nanoplatelets nanofluid using experimental data, Int. Commun. Heat Mass Transf. 82 (2017) 40-48. doi:10.1016/j.icheatmasstransfer.2017.02.003.

[34] A.S. Dalkilic, A. Çebi, A. Celen, O. Yıldız, O. Acikgoz, C. Jumpholkul, M. Bayrak, K. Surana, S. Wongwises, Prediction of graphite nanofluids' dynamic viscosity by means of artificial neural networks, Int. Commun. Heat Mass Transf. 73 (2016) 33-42. 
doi:10.1016/j.icheatmasstransfer.2016.02.010.

[35] M. Gholizadeh, M. Jamei, I. Ahmadianfar, R. Pourrajab, Prediction of nanofluids viscosity using random forest (RF) approach, Chemom. Intell. Lab. Syst. 201 (2020) 104010. doi:10.1016/j.chemolab.2020.104010.

[36] M.A. Marcos, L. Lugo, S. V. Ageev, N.E. Podolsky, D. Cabaleiro, V.N. Postnov, K.N. Semenov, Influence of molecular mass of PEG on rheological behaviour of MWCNT-based nanofluids for thermal energy storage, J. Mol. Liq. 318 (2020) 113965. doi:10.1016/j.molliq.2020.113965.

[37] F. Mashali, E.M. Languri, J. Davidson, D. Kerns, W. Johnson, K. Nawaz, G. Cunningham, Thermo-physical properties of diamond nanofluids: A review, Int. J. Heat Mass Transf. 129 (2019) 1123-1135. doi:10.1016/J.IJHEATMASSTRANSFER.2018.10.033.

[38] R. Sadri, M. Hosseini, S.N. Kazi, S. Bagheri, N. Zubir, G. Ahmadi, M. Dahari, T. Zaharinie, A novel, eco-friendly technique for covalent functionalization of graphene nanoplatelets and the potential of their nanofluids for heat transfer applications, Chem. Phys. Lett. 675 (2017) 92-97. doi:10.1016/j.cplett.2017.02.077.

[39] J. Bin Wu, M.L. Lin, X. Cong, H.N. Liu, P.H. Tan, Raman spectroscopy of graphene-based materials and its applications in related devices, Chem. Soc. Rev. (2018). doi:10.1039/c6cs00915h.

[40] X. Li, L. Zhi, Graphene hybridization for energy storage applications, Chem. Soc. Rev. 47 (2018) 3189-3216. doi:10.1039/c7cs00871f.

[41] S.U. Ilyas, S. Ridha, F.A. Abdul Kareem, Dispersion stability and surface tension of SDSStabilized saline nanofluids with graphene nanoplatelets, Colloids Surfaces A Physicochem. Eng. Asp. (2020). doi:10.1016/j.colsurfa.2020.124584.

[42] S. Chakraborty, P.K. Panigrahi, Stability of nanofluid: A review, Appl. Therm. Eng. 174 (2020) 115259. doi:10.1016/j.applthermaleng.2020.115259.

[43] S.U. Ilyas, R. Pendyala, N. Marneni, Stability of Nanofluids, Eng. Appl. Nanotechnol. (2017) 1-31. doi:10.1007/978-3-319-29761-3_1.

[44] S.U. Ilyas, M. Narahari, R. Pendyala, Rheological characteristics of ultrastable diamond-thermal oil nanofluids, J. Mol. Liq. (2020). doi:10.1016/j.molliq.2020.113098.

[45] S.U. Ilyas, R. Pendyala, M. Narahari, Stability and thermal analysis of MWCNT-thermal oilbased nanofluids, Colloids Surfaces A Physicochem. Eng. Asp. 527 (2017) 11-22. doi:10.1016/j.colsurfa.2017.05.004.

[46] M.J. Rosen, J.T. Kunjappu, Surfactants and Interfacial Phenomena, John Wiley \& Sons, Inc., Hoboken, NJ, USA, 2012. doi:10.1002/9781118228920.

[47] S.M.S. Murshed, P. Estelle, A state of the art review on viscosity of nanofluids, Renew. Sustain. Energy Rev. 76 (2017) 1134-1152. doi:10.1016/j.rser.2017.03.113.

[48] A. Gallego, K. Cacua, B. Herrera, D. Cabaleiro, M.M. Piñeiro, L. Lugo, Experimental evaluation of the effect in the stability and thermophysical properties of water-Al2O3 based nanofluids using SDBS as dispersant agent, Adv. Powder Technol. 31 (2020) 560-570. doi:10.1016/j.apt.2019.11.012.

[49] S. Zeroual, P. Estellé, D. Cabaleiro, B. Vigolo, M. Emo, W. Halim, S. Ouaskit, Ethylene glycol based silver nanoparticles synthesized by polyol process: Characterization and thermophysical profile, J. Mol. Liq. 310 (2020) 113229. doi:10.1016/j.molliq.2020.113229.

[50] J.P. Vallejo, G. Żyła, J. Fernández-Seara, L. Lugo, Rheological behaviour of functionalized graphene nanoplatelet nanofluids based on water and propylene glycol:water mixtures, Int. Commun. Heat Mass Transf. 99 (2018) 43-53. doi:10.1016/j.icheatmasstransfer.2018.10.001.

[51] J.P. Vallejo, S. Gómez-Barreiro, D. Cabaleiro, C. Gracia-Fernández, J. Fernández-Seara, L. Lugo, Flow behaviour of suspensions of functionalized graphene nanoplatelets in propylene glycol-water mixtures, Int. Commun. Heat Mass Transf. 91 (2018) 150-157. doi:10.1016/j.icheatmasstransfer.2017.12.001.

[52] J. Liebrecht, X. Si, B. Sauer, H. Schwarze, Investigation of drag and churning losses on tapered roller bearings, Stroj. Vestnik/Journal Mech. Eng. 61 (2015) 399-408. doi:10.5545/svjme.2015.2490.

[53] Swep, Industrial handbook introudction - oil as a heat transfer fluid, (n.d.). doi:https://www.swep.net/industrial-handbook/industrial-handbook/.

[54] Yukun Engineering Standards, Data Sheets: Formulas/Nomograms (Part 4) Viscosity Vs. 
Temperature Charts, n.d.

[55] H. Nguyen-Schäfer, Applied tribology in the oil-film bearings, in: Springer Tracts Mech. Eng., 2015. doi:10.1007/978-3-319-17644-4_9.

[56] Encyclopedia of Lubricants and Lubrication, 2014. doi:10.1007/978-3-642-22647-2.

[57] J.-B. Wu, M.-L. Lin, X. Cong, H.-N. Liu, P.-H. Tan, Raman spectroscopy of graphene-based materials and its applications in related devices, Chem. Soc. Rev. 47 (2018) 1822-1873. doi:10.1039/C6CS00915H.

[58] D. Cabaleiro, M.J. Pastoriza-Gallego, C. Gracia-Fernández, M.M. Piñeiro, L. Lugo, Rheological and volumetric properties of TiO2-ethylene glycol nanofluids, Nanoscale Res. Lett. 8 (2013) 286. doi:10.1186/1556-276X-8-286.

[59] D. Gómez-Díaz, J.M. Navaza, Rheology of aqueous solutions of food additives: Effect of concentration, temperature and blending, J. Food Eng. 56 (2003) 387-392. doi:10.1016/S02608774(02)00211-X.

[60] G. Tammann, W. Hesse, Die Abhängigkeit der Viscosität von der Temperatur bie unterkühlten Flüssigkeiten, Zeitschrift Für Anorg. Und Allg. Chemie. 156 (1926) 245-257. doi:10.1002/zaac.19261560121.

[61] E.I. Cherecheș, J.I. Prado, C. Ibanescu, M. Danu, A.A. Minea, L. Lugo, Viscosity and isobaric specific heat capacity of alumina nanoparticle enhanced ionic liquids: An experimental approach, J. Mol. Liq. (2020). doi:10.1016/j.molliq.2020.114020.

[62] A. Karimipour, S. Ghasemi, M.H.K. Darvanjooghi, A. Abdollahi, A new correlation for estimating the thermal conductivity and dynamic viscosity of $\mathrm{CuO} /$ liquid paraffin nanofluid using neural network method, Int. Commun. Heat Mass Transf. 92 (2018) 90-99. doi:10.1016/j.icheatmasstransfer.2018.02.002.

[63] N. Zhao, Z. Li, Experiment and artificial neural network prediction of thermal conductivity and viscosity for alumina-water nanofluids, Materials (Basel). 10 (2017). doi:10.3390/ma10050552.

[64] A. Barati-Harooni, A. Najafi-Marghmaleki, A. Mohebbi, A.H. Mohammadi, On the estimation of viscosities of Newtonian nanofluids, J. Mol. Liq. 241 (2017) 1079-1090. doi:10.1016/j.molliq.2017.06.088.

[65] J.F.-A. of statistics, undefined 2001, Greedy function approximation: a gradient boosting machine, JSTOR. (n.d.).

[66] M. Si, K. Du, Development of a predictive emissions model using a gradient boosting machine learning method, Environ. Technol. Innov. 20 (2020) 101028. doi:10.1016/j.eti.2020.101028.

[67] J. Jiang, Y. Tzeng, Mechanisms of suppressing secondary nucleation for low-power and lowtemperature microwave plasma self-bias-enhanced growth of diamond films in argon diluted methane, AIP Adv. 1 (2011) 042117. doi:10.1063/1.3656241.

[68] M. Muthuraj, J. Bensam Raj, J. Sunil, Experimental Investigation on the Influence of Graphene Nanoplatelets Dispersion on the Thermal Conductivity of Sunflower Oil, Int. J. Nanosci. 19 (2020) 1950011. doi:10.1142/S0219581X1950011X.

[69] T.S. Krishnakumar, S.P. Viswanath, S.M. Varghese, J. Prakash M, Experimental studies on thermal and rheological properties of Al2O3-ethylene glycol nanofluid, Int. J. Refrig. 89 (2018) 122-130. doi:10.1016/j.ijrefrig.2018.03.008.

[70] M. Afrand, D. Toghraie, B. Ruhani, Effects of temperature and nanoparticles concentration on rheological behavior of Fe3O4-Ag/EG hybrid nanofluid: An experimental study, Exp. Therm. Fluid Sci. 77 (2016) 38-44. doi:10.1016/j.expthermflusci.2016.04.007.

[71] S. Hamze, D. Cabaleiro, T. Maré, B. Vigolo, P. Estellé, Shear flow behavior and dynamic viscosity of few-layer graphene nanofluids based on propylene glycol-water mixture, J. Mol. Liq. 316 (2020) 113875. doi:10.1016/j.molliq.2020.113875.

[72] S.U. Ilyas, R. Pendyala, M. Narahari, Rheological behavior of mechanically stabilized and surfactant-free MWCNT-thermal oil-based nanofluids, Int. Commun. Heat Mass Transf. 87 (2017). doi:10.1016/j.icheatmasstransfer.2017.07.015. 